Portland State University

PDXScholar

Spring 6-11-2018

\title{
An Analysis of the BizX Commercial Trade Exchange: the Attitudes and Motivations Behind Its Use
}

Ján André Montoya

Portland State University

Follow this and additional works at: https://pdxscholar.library.pdx.edu/open_access_etds

Part of the Economics Commons, and the Urban Studies and Planning Commons Let us know how access to this document benefits you.

Recommended Citation

Montoya, Ján André, "An Analysis of the BizX Commercial Trade Exchange: the Attitudes and Motivations Behind Its Use" (2018). Dissertations and Theses. Paper 4488.

https://doi.org/10.15760/etd.6372

This Thesis is brought to you for free and open access. It has been accepted for inclusion in Dissertations and Theses by an authorized administrator of PDXScholar. Please contact us if we can make this document more accessible: pdxscholar@pdx.edu. 
An Analysis of the BizX Commercial Trade Exchange:

The Attitudes and Motivations Behind Its Use

by

Ján André Montoya

A thesis submitted in partial fulfillment of the requirements for the degree of

Master of Urban Studies

Thesis Committee:

Greg Schrock, Chair

Lisa Bates

Sheila Martin

Portland State University

2018 


\begin{abstract}
The Global Financial Crisis underscored both the complexity and brittleness of the global financial system, especially for small to medium enterprises dependent on the current banking regime for credit. More than ever, we have also begun to see the disentanglement of small businesses from traditional banks at the local and regional level in the form of CDFIs, fintech alternative lending, and now complementary currencies. Through interviews with the management and members of the BizX complementary currency this study asks what the attitudes and motivations are behind its offering and use. In addition, it inquires into the economic and psychological benefits that arise from it. Often referred to as a barter network but more accurately described as a commercial trade exchange, BizX and its member's attitudes and motivations differ significantly from other complementary currencies in its apolitical stance to trade and large national and international membership. Its value proposition, the development of hyper-local economies, is real but its aspirational attempt at creating a robust community similar to its community currency siblings is questionable. Nonetheless, its value as an economic development tool is undeniable and the research concludes it implementation within a larger structure of economic development self-reliance strategies should be given serious consideration for future planning.
\end{abstract}




\section{DEDICATION}

To all the people who want to leave this world better than they found it. 


\section{ACKNOWLEDGEMENTS}

My deepest thanks to all my friends and family who supported my return to school at forty-four years of age. Special mention to my parents for all their encouragement and love. Especially my mother whose moral support knows no bounds. Also, I thank Dr. Sheila Martin and Dr. Lisa Bates for being a part of my committee. In addition, my great thanks to Leander Bindewald for his council on all aspects of complementary currencies. I hope we have a chance to work together again in the near future. Finally, a big whopping thanks to Dr. Greg Schrock for his patience with my "origami” writing and whose dedication to my academic success was of central importance to this thesis.

\section{All of you rock!}




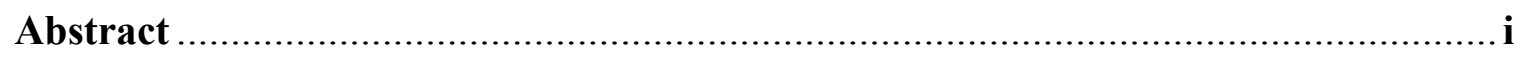

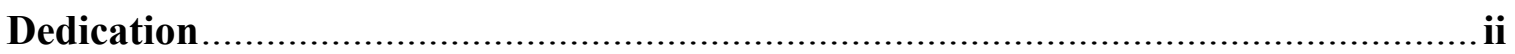

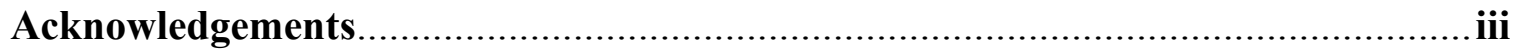

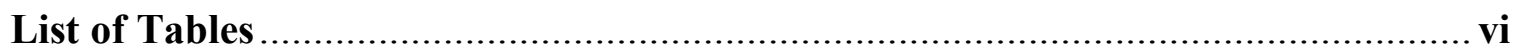

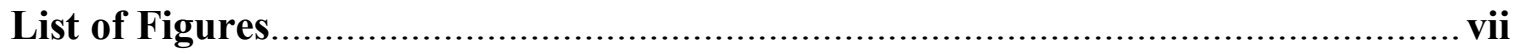

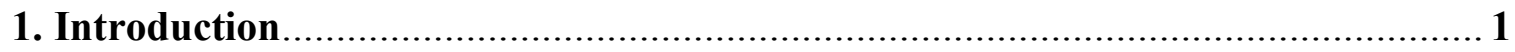

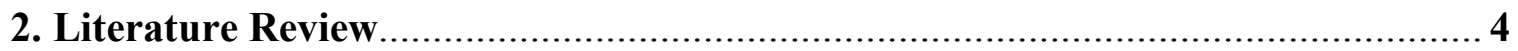

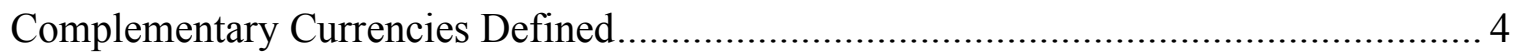

Typology

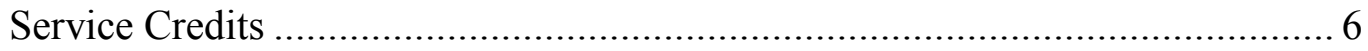

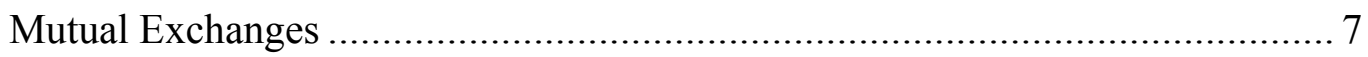

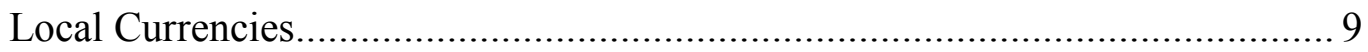

Barter Markets/Commercial trade Exchanges (CTEs) …………………......... 10

The Latest Classification: Blockchain Based Digital Currencies ........................ 11

CTEs and Their Role in Economic Development ................................................. 12

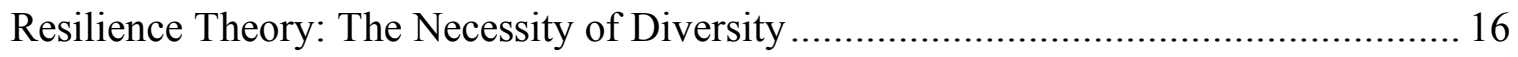

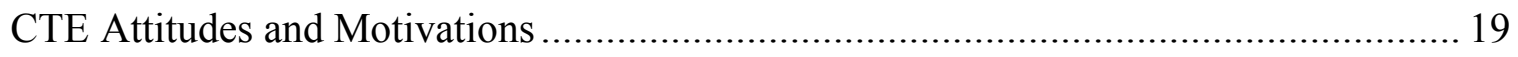

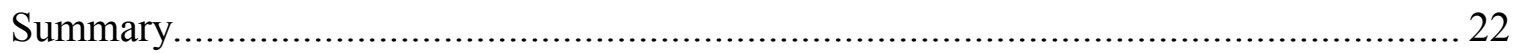

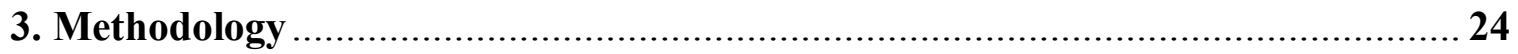

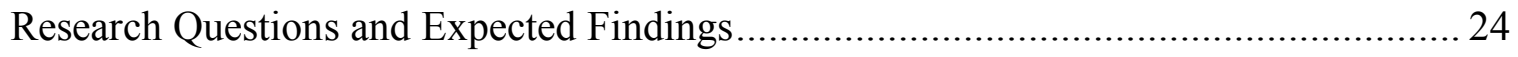

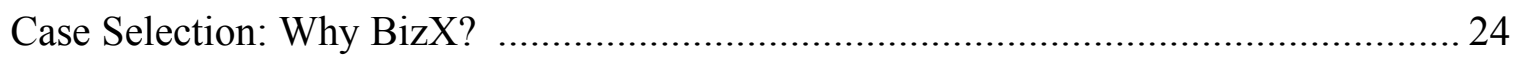

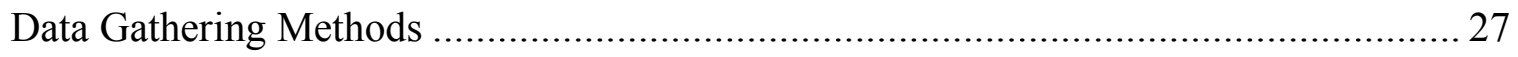

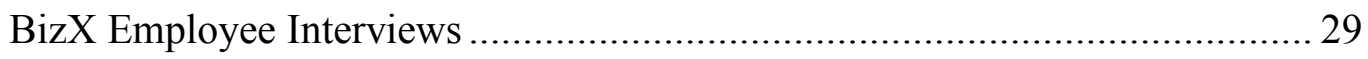

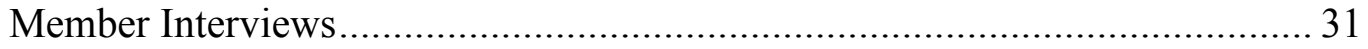

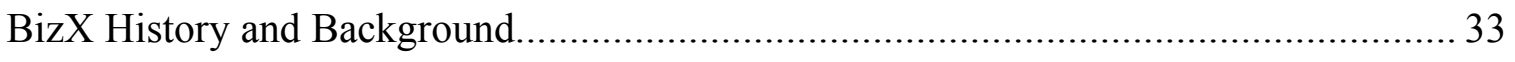

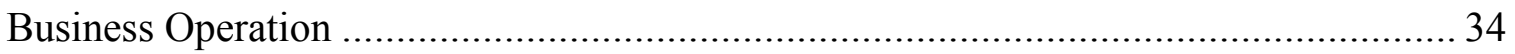

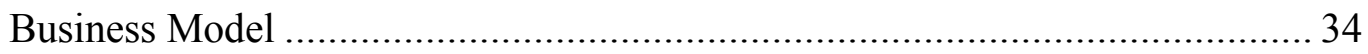

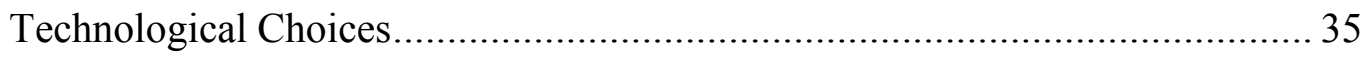

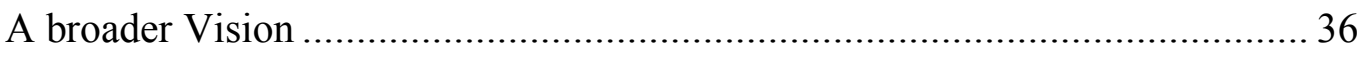




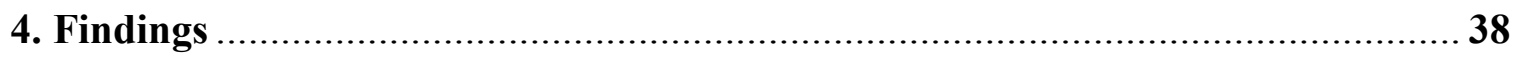

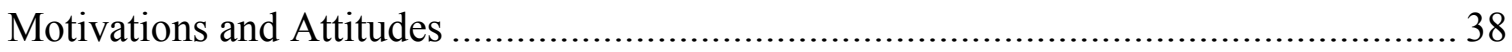

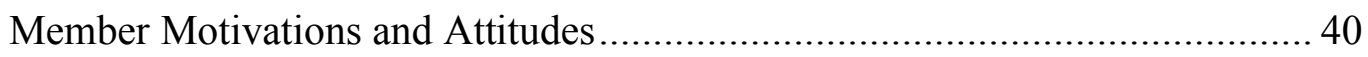

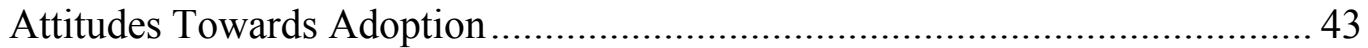

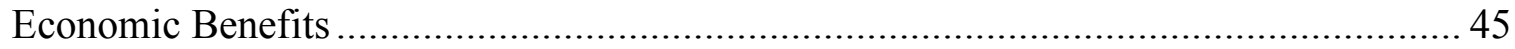

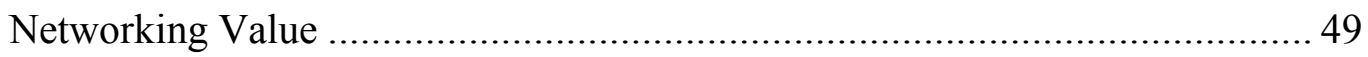

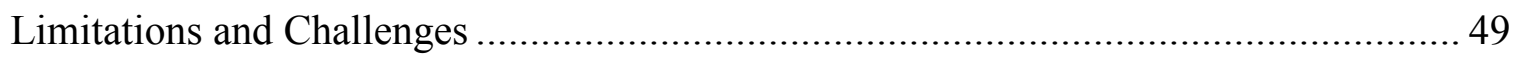

Conclusion: Significant Value Despite Limitations …………………..................... 52

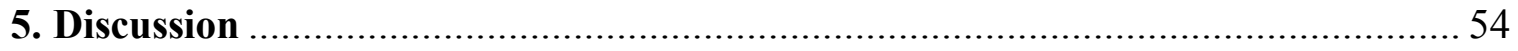

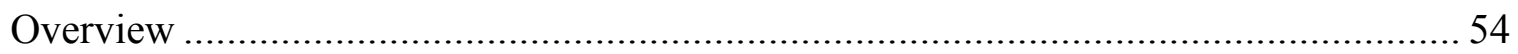

BizX Community and Economic Network Limitations................................................ 56

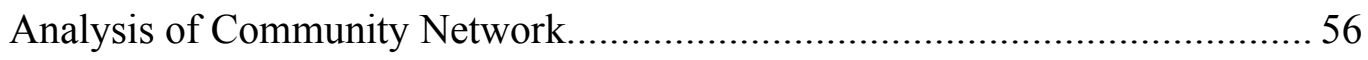

Analysis of Economic Network ………….................................................... 57

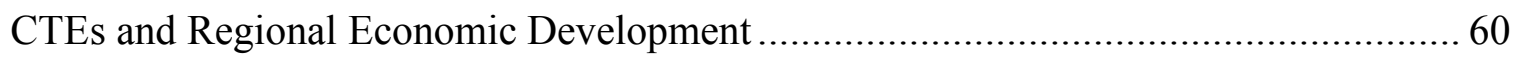

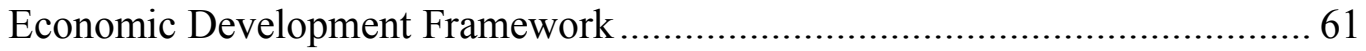

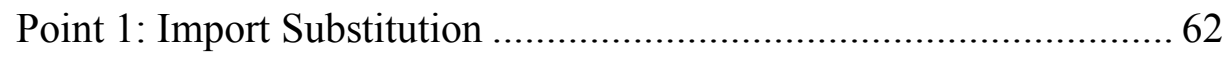

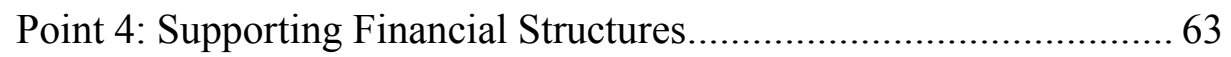

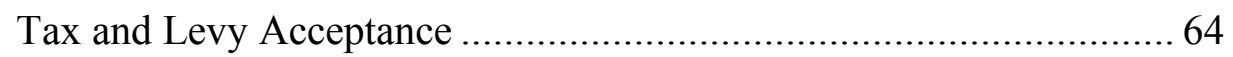

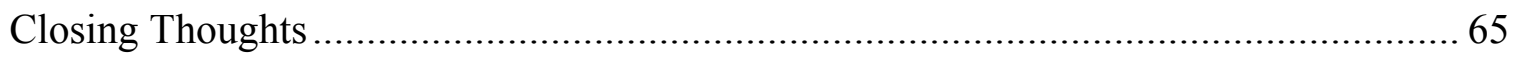

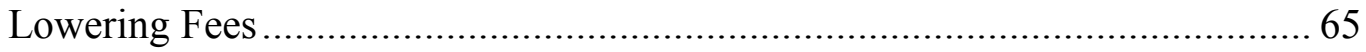

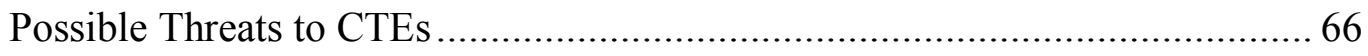

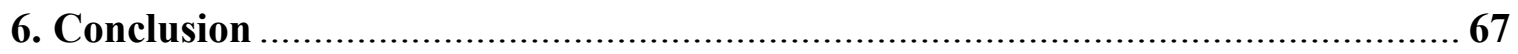

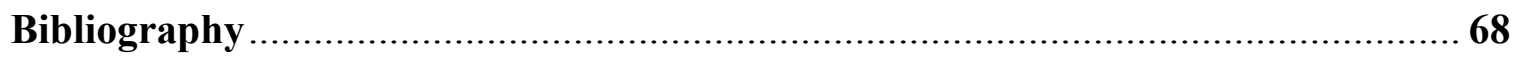

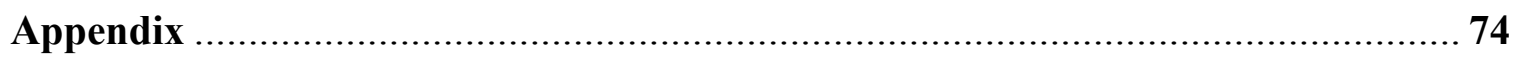

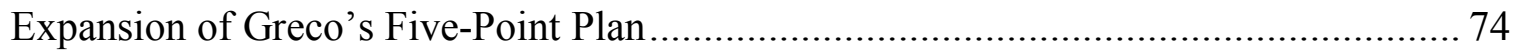

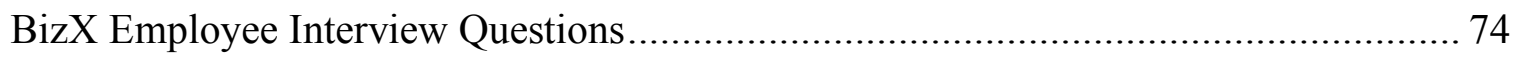

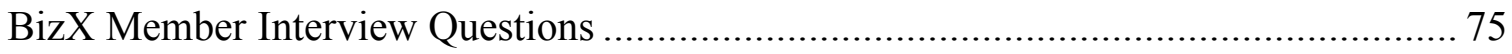




\section{LIST OF TABLES}

Table 1: Complementary Currencies by Type and Characteristics ............................... 12

Table 2: Breakdown of Businesses Interviewed................................................. 28

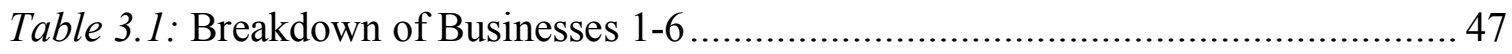

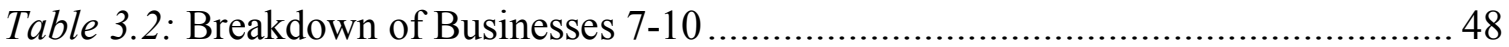




\section{LIST OF FIGURES}

Figure 1: Balance Between Efficiency and Resilience.............................................. 18

Figure 2: BizX's Three Tier Pricing Platform .......................................................... 35

Figure 3: SMEs are the Main Source of Jobs in the Business Sector ......................... 61 


\section{INTRODUCTION}

Complementary currencies (CCs) have been in existence since Dynastic Egypt. However, CCs have only been a serious field of study within the past twenty years and it has only been in the last nine that there has been a notable increase in scholarship. This is in large part due to the Global Financial Crisis (GFC) in 2008-2009. The GFC underscored both the complexity and brittleness of the global financial system, especially for small to medium enterprises (SME) dependent on the current banking regimes for credit. As such, communities affected have looked far and wide for ways that would help them weather their financial difficulties. CCs have offered a valuable tool for many to help link supply to demand when money was scarce and rebuild a sense of community that globalization and our neoliberal financial system have fractured. In addition, with the ongoing uncertainty with global warming, resource depletion, and shoddy economic policies by governments resulting in cycles of debt and austerity, communities are looking for ways to insulate themselves from further economic trauma.

The USA with its record levels of debt and political gridlock has caused many countries to begin looking for ways to disentangle themselves from its monetary hegemony over the international money system. (Otero-Iglesias \& Steinberg, 2013) This is large part because many international transactions such as oil are done through the dollar. Economic shocks ripple globally when the US economy experiences disruptions especially affecting countries like China who peg the value of their currency to the dollar. 
We have also begun to see this disentanglement at the national and regional level with the advent of fintech alternative lending, ${ }^{1}$ the rise of interest in import substitution often seen in buy local strategies, the growth of transition towns, and now CCs.

Economic development planners know more than ever their approach to planning must be regional rather than city by city if they are to promote resilience on the part of businesses. This is especially so with SMEs. Their greater connectivity and increase in multiplier effects can only come from those economic development strategies that focus on business retention, alternative lending, import substitution and other self-reliance strategies discussed later.

The purpose of this paper was to gain insights into the attitudes and motivations behind the use of the BizX CC. I was interested to see if a CC barter network such as BizX, which is more accurately described as a commercial trade exchange (CTE), would bear out my readings of many of the other types of CCs I studied. Did they approach it from a perspective of economic and or social/ecological justice and if so why? To what degree (if any) did they find it of value? And if so, what role could it play could it be within a larger urban studies framework of economic and community development with SMEs in mind?

My findings were a mixed bag but clearly indicated that the economic value proposition was real and had considerable potential. In addition to helping SMEs become resilient during times of economic disruption, BizX showed notable potential to help them grow. However, the strong community bonds I hypothesized did not present

1. Fintech alternative lending refers to firms whose products and services help existing SMEs and startups bypass the use of a traditional banks through the use of technology. Examples of fintech alternative lending are crowdfunding and P2P marketplace lending. 
themselves in a meaningful way despite its operators' community-focused manifesto. BizX's main benefit to its members was first and foremost economic.

This paper does not attempt to address many of the mechanical questions that a regional economic plan that gave serious consideration to supporting SMEs using CCs would ask. My intention is merely to use the existing CC literature and my research findings to create further discussion around the integration of CCs within a regional economic system and for local economic development planning. This is important because many of the problems that were mentioned earlier are the result of outdated economic models that have supported and attained certain objectives but to great social and environmental expense. These problems need new approaches to solve them. Having studied CCs for the past four years, I sincerely believe that CCs will play an increasing and integral part of their solution and help further the goal of just, equitable, and effective economic development. 


\section{LITERATURE REVIEW}

\section{COMPLEMENTARY CURRENCIES DEFINED}

A helpful starting point is to define and contextualize the broader framework of complementary currencies (CCs). This is especially important as I will be comparing and contrasting different types of CCs, especially commercial trade exchanges (CTE), throughout this paper. I start with the continued debate by academics and practitioners as to what constitutes a $\mathrm{CC}$ beyond it being a medium of exchange, a unit of account, and often (but not always) a store of value that is not state-issued. This has been in part difficult to do because of the constant innovations that mutate their makeup. However, the CC scholar Jérôme Blanc typologizes them by territory, community and economic characteristics and sees that for a currency to fall with the CC family it must be innovative in a way that expands a social justice or eco-conscious function. He writes:

...they (CCs) are designed and implemented mostly by civil society, mostly locally and grassroots, and mostly in a democratic way, emphasizing the citizen's appropriation and redefinition of money in a participatory process. (2011, p. 6).

As Blanc sees it, large amounts of commercial activity are not the benchmark for a successful economy. It is how that activity supports the social fabric of their community that make it of true value. This is seen especially so in time banks and LETS systems which are discussed shortly. Other examples seen in community currencies such as the 
Lewes Pound and Brixton Pound in the UK, and BerkShares in the USA. All of them highlight the importance of community building and a larger social good as part of their value proposition. In addition, there are strong and politically active undercurrents with other community currencies. One out of many can be seen in Spain's 15M Social Movement, a grassroots organization similar to the U.S.A.'s Occupy Movement. In Madrid, 15M has set up ten Time Banks to not only help build support for the local economy but also as a form of opposition to "dominant economic and political practices and discourses." (Hughs, 2015, p. 8)

From Blanc's perspective, state-issued "fiat" 2 currencies (e.g. dollar, yen, euro) and any other currencies that incorporate a financial profit motive are excluded. Such a "purist" approach disqualifies many of the digital currencies in existence (e.g. bitcoin and etherium) as well as point systems (e.g. frequent flyer miles issued by airlines) and forprofit CTEs like BizX. However, others such as currency expert Bernard Lietaer see Blanc's definition as limiting and provides a broader one. He writes:

A complementary currency ... is an agreement to use something else than legal tender (i.e. national money) as a medium of exchange, with the purpose to link unmet needs with otherwise unused resources. (Lietaer \& Hallsmith, p. 2)

Lietaer sees the culprits of many of today's societal ills as the global currency monocultures (e.g. dollar, yen, euro) and the current financial banking regime. In his paper Options for Managing a Systemic Bank Crisis and in many of his other writings. 
'(Lietaer, Ulanowicz, \& Goerner, 2009) Lietaer sees a diversity of currency systems as necessary tools for economic justice and resilience. They do this in part by loosening the stranglehold that today's banking regime holds over credit, thereby creating greater resilience against the effects of the boom and bust economic cycles that are baked into the DNA of today's financial system (his CC resilience theory is detailed later).

For the purpose of this paper, I will adopt Lietaer's broader definition to frame my research of the BizX CTE. Furthermore, I will make a distinction within the CC family with regards to their philosophical underpinnings. "Community currencies" are a particular type of CC that is predicated on values of social justice and or ecoconsciousness, is not-for-profit, and limited to a particular geographic location or region. CCs that are not based on social justice and or environmental concerns, are for-profit, and are unrestricted by geography will be referred to as "open currencies."

\section{TYPOLOGY}

CCs come in a multitude of shapes and sizes and exist all over the world. Some are highly localized while others operate across all borders. Each one is unique to the population it serves but CC researchers Gil Seyfang and Noel Longhurst (2013) broadly organize them into four classifications, to which I add a fifth category and summarize in table 1 .

\section{- Service Credits -}

Generally known as "timebanks," service credits are the most common of CCs and are usually found in city areas where people have been socially excluded, have health 
problems, and are elderly. They work as formalized and reciprocal volunteering schemes whereby enrolled members list services they wish to offer and receive and are matched with the aid of a broker. (Seyfang \& Longhurst, 69) Service credits are time-based and egalitarian in nature and represent a "radical rejection of contemporary labor valuation" as all types of work exchanged on an hourly basis are counted as the same. (Seyfang \& Longhurst, 69) There are no checks, coins, or notes in the currency and hours are tracked through a computerized ledger system. They generally work as a community development tool and can be thought of a system of community loyalty points. The more a person contributes the more they can receive from other participating community members. Social care services are most often provided. However, time banks are not usually seen as a tool to develop local SMEs or new ways of production but primarily are a "way of recognizing work that society often devalues." (North, Chapter 6)

Created by the legal professor Edward Cahn in 1986, service credit systems have since spread around the world and have strong networks in the USA and UK. Notable examples are the Dane County Time Bank in Madison and time bank clearing houses in the USA (https://timebanks.org) and in the UK that has dozens more (http://www.timebanking.org).

\section{- Mutual Exchanges -}

Similar to service credits, members of a mutual exchange list their wants and needs in a listing. However, they bypass the need for a broker and members access each other's offerings directly. They are created through the spending of one members credit which equals another's debit to the system with accounts always summing to zero (Seyfang \& 
Longhurst, 69). Money is injected into system through the creation of "commitments." A possible scenario that I paraphrase ${ }^{3}$ from North is of a fictitious mutual exchange called "Transact" might look like the following:

- Julia, a hair dresser, wants her car washed and looks through Transact's businesses listing.

- She finds Brad who is willing to do it for 10 Transact credits.

- Julia agrees and Brad washes her car.

- Julia then sends him the amount of 10 Transacts via Transact's mobile payment app which it is instantly credited to his account.

- These 10 Transacts are also debited to Julia's Transact account.

- Brad then decides to spend his 10 Transacts on an exercise session with Robert.

- Robert provides the session and is paid 10 Transacts by Brad which is then deposited in Roberts Transact account.

- Afterwards, Robert decides to get a hair-cut and goes to Julia for a 10 Transact trim. (North, Chapter 5)

As mentioned, all transactions equal to zero in a mutual exchange. Care must be taken within these systems that balances of members do not get to credited or debited too high. This prevents members from acquiring balances too high to reasonably spend and debts that are difficult to pay back. The most noted of these are mutual exchanges are called local exchange trading systems (LETS) which were pioneered by Michael Linton in Vancouver, Canada as a way to mitigate economic downturns. (Bindewald et. al., pg. 35)

3. In addition to the name "Transact," I also contemporize the transaction by using a mobile app as the tool of payment. North's example uses paper checks. 
Mutual exchanges also differ from time banks in that they operate within a defined geographic area and their value can be linked to a fiat currency. They also offer interest-free credit which can only be spent within the network. Traditionally paperbased, they can also be a mixture of time and currency. (Seyfang \& Longhurst, 69) Though they are targeted towards supporting local economies the greatest impact has been with their social and community-building benefits. (Seyfang \& Longhurst, 69)

\section{- Local Currencies -}

These are paper-based currencies that are grassroots spawned and take the form of cooperatives and nonprofits. Unlike mutual exchanges and service credits they have the ability to scale up from the local to the regional level. They trace their roots to Depression-era stamp scrip which were created to increase local economic activity among business members at a time of extreme financial scarcity. (Seyfang \& Longhurst, 70) They are also unlike service credits and mutual exchanges in that they are not tied to commitments and are used the same as conventional money increasing their fungibility. In addition, they are exchangeable for a national currency albeit often with an exchange cost which is done to incentivize local spending.

However, local currencies have started offering a mixture of digital payment as well as paper notes. With some currencies such as the Bristol Pound, local governments will even accept them for the payment of local taxes. (Bristol Pound) Other notable examples are Chiemgaur in Germany (http://chiemgauer.info) and BerkShares (http://berkshares.org) in the USA. 


\section{- Barter Markets /Commercial Trade Exchanges (CTEs) -}

A hybrid of local currency and mutual exchanges, CTEs enable the exchange of goods and services, usually within site-specific local markets. Users are usually part of a club which gives them an interest-free loan to begin spending. (Seyfang \& Longhurst, 71) They differ from mutual exchanges in that money is not injected into the system by commitments, they are not convertible to a fiat currency, and can be for-profit giving them community and open currency properties. Examples are the $\mathrm{Wir}^{4}$ in Switzerland, Sardex in Sardinia, Italy, and BizX in the United States. In addition, many CTEs offer interest-free or low-coast loans relative to traditional banks. However, in some cases the savings gained are offset by high transaction fees.

Three CTE studies tracked commercial and corporate trade exchanges from 19741995 in the USA and found that commercial exchanges grew from 45 to 1,248 while corporate exchanges grew 850 to 7,126 . (Stodder, 1998) Since then, this amount has decreased but not their value. Greco notes that CTEs have undergone a process of consolidation as larger ones have bought smaller ones resulting in more trading opportunities for its members. (2008, Chapter 15)

\footnotetext{
4. The Wir is the largest of all CCs and is a CTE in Switzerland and has been in existence since 1934. It is anchored to the Swiss Franc but is not exchangeable for it. (Stodder, 2009) It differs from other CTEs in that is made up of both B2B and C2C members. C2C member data was unobtainable but in 2015 it had 80,000 participating businesses (De la Rosa \& Stodder, 122) and in 2012 generated 1.46 billion in turnover in Wir credits. (De la Rosa \& Stodder, 121)
} 


\section{- The Latest Classification: Blockchain Based Digital Currencies -}

A category of CC that is outside of Seyfang and Longhurst's typology are the open currencies that sprang into existence with Bitcoin ${ }^{5}$ in 2009. Despite its dominance, there are dozens of competitors with the closest being etherium, litecoin and ripple. They are geographically unbounded and work without any centralized authority or issuer. One of their lauded benefits is their anonymous peer-to-peer spending characteristics. Though democratic in their issuance (one only needs access to the internet to buy and use it) their creation through a process called "mining" requires expensive computing hardware that leaves many unable to manufacture their own without being in a "pool" of other miners. They are innovating quickly and have acquired other financial properties such as the ability to create strong contractual agreements between parties that are ledgerized into their blockchain. This innovation extends to their taking on local currency characteristics and other financial instruments. Berkeley is currently creating a local cryptocurrency for buying municipal bonds. (Holder, 2018)

5. Bitcoin and its competitors are mined, bought, and sold in large part out of the hope they will grow in value and bring a considerable ROI. In addition, they are generally offered by for-profit organizations. Hence, I argue they are open currencies. 


\begin{tabular}{|c|c|c|c|c|c|}
\hline & $\begin{array}{l}\text { SERVIQE } \\
\text { GREDITS }\end{array}$ & $\begin{array}{c}\text { MUTUAL } \\
\text { EXOHANGES }\end{array}$ & $\begin{array}{c}\text { LOBAL } \\
\text { GURRENGIES }\end{array}$ & $\begin{array}{l}\text { BARTER } \\
\text { MARKETSI } \\
\text { BTES }\end{array}$ & $\begin{array}{c}\text { DIGITAL } \\
\text { BURRENGIES }\end{array}$ \\
\hline $\begin{array}{l}\text { GEOGRAPHIBALIY } \\
\text { BOUNDED }\end{array}$ & Yes & Yes & $\begin{array}{c}\text { Yes } \\
\text { (But can expand } \\
\text { regionally) }\end{array}$ & $\begin{array}{c}\text { No } \\
\text { (But tend to } \\
\text { be local) }\end{array}$ & No \\
\hline $\begin{array}{l}\text { ERONOMIG VS } \\
\text { SOCIAL BASED }\end{array}$ & Social & $\begin{array}{c}\text { Mixture } \\
\text { (Primary impact } \\
\text { is community- } \\
\text { building) }\end{array}$ & $\begin{array}{c}\text { Economic } \\
\text { (Also supports } \\
\text { regional pride and } \\
\text { placemaking) }\end{array}$ & Economic & Economic \\
\hline $\begin{array}{l}\text { EXBHANGED FOR } \\
\text { FIAT GURRENGY }\end{array}$ & No & $\begin{array}{c}\text { Yes } \\
\text { (But tends not } \\
\text { to be) }\end{array}$ & $\begin{array}{c}\text { Yes } \\
\text { (But only for } \\
\text { partial value) }\end{array}$ & No & $\begin{array}{c}\text { Mixture } \\
\text { (Rewards } \\
\text { systems cannot) }\end{array}$ \\
\hline $\begin{array}{l}\text { TANGIBLE VS } \\
\text { ELEGTRONIG }\end{array}$ & Electronic & Mixture & Mixture & Electronic & Electronic \\
\hline BROKER & Yes & No & No & Yes & No \\
\hline $\begin{array}{l}\text { LINKED TO FIAT } \\
\text { CURRENCY }\end{array}$ & No & Mixture & Yes & Yes & $\begin{array}{c}\text { Yes } \\
\text { (Some virtual } \\
\text { currencies } \\
\text { do not) } \\
\end{array}$ \\
\hline $\begin{array}{l}\text { TIME OR } \\
\text { GURRENGY } \\
\text { BASED } \\
\end{array}$ & Time & Mixture & Currency & Currency & Currency \\
\hline $\begin{array}{c}\text { OFFER INTEREST } \\
\text { FREE CREDIT }\end{array}$ & No & Yes & No & Yes & No \\
\hline
\end{tabular}

Table 1: Complementary currencies by type and characteristics

\section{CTES AND THEIR ROLE IN ECONOMIC DEVELOPMENT}

There is little literature that deals specifically with CCs from an economic development perspective apart from Thomas Greco's who outlines a framework that I discuss later. Nonetheless, there are worthwhile readings and ways to contextualize CCs within contemporary economic development practice. Osgood et. al. provides a historical "waves" perspective and identifies three while Leigh \& Blakely identify two more. First- 
wave strategies focus on firm attraction for economic growth, often with large tax and infrastructure incentives. (Osgood et. al., p. 334) Second-wave strategies turned the focus inward by "leveraging economic development efforts to retain and expand existing firms." (Osgood et. al., p. 334) In practice, this focused on small business assistance and entrepreneurial support through alternative forms of lending via community development financial institutions $(\mathrm{CDFI})^{6}$ and workforce training. Finally, third-wave strategies focused on quality-of-life, environmental concerns, social costs of growth, and redistribution issues as CCs do. (Osgood et. al., p. 336) Leigh and Blakely see development through a similar lens but instead of waves frame it through "phases." (Leigh \& Blakely, Chapter 2) Their framework goes into greater detail as they detail a fourth and fifth phase. The fourth phase, sustainable local economic development (SLED), emphasized self-sufficiency over an export-based economy and development over growth while the fifth phase relied on market solutions while promoting metropolitan or regional strategies. (Leigh \& Blakely, Chapter 2) It is Osgood et. al.'s wave two and Leigh \& Blakely's phase four strategies that CTEs fall best within for reasons previously mentioned.

However, advocates for CCs in general, and CTEs in particular, view them as part of a broader, alternative approach to economic development. As mentioned, the literature I did find that squarely placed CTEs within an economic development framework was

6. Eberts describes CDFIs as "mission-driven financial institutions that provide financial products and services to people and communities underserved by traditional financial institutions." (2005, pg. 207) They were a response to the "war on Poverty" by the federal government in the 1960s and 1970s. (Eberts, pg. 207) Since then, they have become a viable alternative lending tool for economic developers to help SMEs that do not qualify for loans from traditional banks. 
written by economist Thomas Greco. His framework closely parallels the "place-based" economic approach proposed by Williamson et. al. (2002) who see it as an alternative way to deal with globalization, the race to the bottom for firm attraction, and the perniciousness of urban sprawl. These "triple threats" they argue undermine the fabric of communities and as a result democracy as well. (Williamson et. al., 2002, Chapter 1) Imbroscio constructs an early outline of this place-based approach in a self-reliance strategy that emphasizes SME development and the focus on "resource flows" that mitigates economic resource leakage. (1995, p. 841) Later, Williamson et. al. also devote an entire chapter in their book to expanding this strategy by fleshing out in further detail the strengthening of local multipliers through import-substitution, SME development, localized investment instruments, and interestingly, local currencies. (2002, Chapter 7) They make note of the promise of scrip currencies developed in the United States and specifically Ithaca HOURs (however, they say nothing about the role of CTEs). Additional writings by the Schumacher Society (which has since been renamed the Schumacher Center for New Economics) also espouse the benefits of similar self-reliance strategies as early as 1973 and have a myriad of writings on their website ${ }^{7}$ about the benefits of local currencies. (Swann, 2001) (Kennedy, 2004) Robert Swann, the Schumacher Society's founder, even went so far as to initiate a local currency called the Exeter that was based on a basket of currencies. ${ }^{8}$ (SCNE)

7. The site can be visited at http://www.centerforneweconomics.org. A simple search of their database using the keywords "local currency" will reveal an abundance of writings.

8. It never came to fruition because the co-creators took ill and died. (Lindstrom \& Witt, 2004) 
Returning to Greco's economic development outline of CTEs, he asserts that they, in conjunction with other measures, can ensure the health of SMEs. His five-point plan proposes:

1. Institute measures that promote import substitution

2. Provide an alternative medium that is independent of any political currency and banking establishment

3. Issue a supplemental regional currency

4. Develop basic support structures that strengthen the local economy and enhance the community's quality of life

5. Develop an independent value standard and unit of account. $(2008$, Chapter 16)

It is points one and four that would be most applicable to a local development agency or CDFI. Buy local campaigns are nothing new and there is a solid alternative lending infrastructure that already exists with the USA (although greatly underfunded). (Okello, 2014) Point two is already well-founded as CTEs exist across the country. Point three is partially in place as a CTE trade association, the International Reciprocal Trade Association (IRTA), ${ }^{10}$ already exists. However, it has not procured an agreement about a uniform credit instrument between its members which precludes a

9. For an expanded description of all points see appendix 1.

10. IRTA is the largest CTE association in the world and has been in existence since the 1970s. As of 2016, IRTA has over 100 members in the commercial barter and complementary currency sectors. They span over four continents and come from the U.S., Canada, Great Britain, Australia, China, Singapore, New Zealand, Italy, Poland, Portugal, France, Holland, Brazil, Mexico, Turkey, Puerto Rico, Thailand, Saudi Arabia the UK and Sardinia. (IRTA) 
unified regional currency. Point four deals with an alternative lending infrastructure that is independent of traditional banks and which CCs fit within. Point five is clearly beyond the scope of any regional economic development plan but there exists the theoretical framework for a global currency called the Terra backed by a basket of commodities. (Lietaer, 2004)

\section{RESILIENCE THEORY: THE NECESSITY OF DIVERSITY}

It is worthwhile to illustrate how resilience in an economic system is created by diversity using a theoretical framework. It allows our understanding of that system to be more holistic and helps answer the question of why CCs should be used. It does this by clarifying the tradeoffs between monoculture currency systems (which we currently live in) that are efficient and those that have a diversity of them making them more resilient (which is what CTEs provide). (Marvasti \& Smyth, 1998) (Stodder, 2009)

According to Lietaer, CCs' economic resilience properties are explained through

theories based on universal system flow that are grounded in natural eco-systems such as Self-organization Theory, Universality Theory, and Information Theory or Non-linear Dynamic Theory (Lietaer et al., 7). Combined, they create the unified systems flow theory that has its roots in research of natural eco-systems. The systems flow theory posits that all flow systems follow the universal properties of efficiency and resilience. These properties are defined as the following:

Efficiency - a network's capacity to perform in a sufficiently organized and efficient manner. (Lietaer et al., 7). 
Resilience - a networks reserve of flexible fallback positions and diversity of actions that can be used to meet the exigencies of novel disturbances and the novelty needed for on-going development and evolution. (Lietaer et al., 7).

As seen in figure 1, related characteristics to resilience are diversity, which is the existence of multiple inputs and outputs within a given network and their interconnectivity. We can see this diversity in the various types of CCs that address the needs of the various sizes of the communities that use them. The type and amount of inputs and outputs for an economically disadvantaged community will differ from one that is not. One that is disadvantaged would do better with a service credits system because of its relatively low costs to implement and maintain. This differs from a paperbased currency which are used by economically advantaged communities and has high startup costs and the replenishment of the currency makes it relatively expensive to sustain.

According to resilience theory, resilient systems have greater diversity and connectivity and are resistant to downturns because there are more pathways to connect inputs to outputs when blockages or disconnections occur. However, an over-abundance of diversity and interconnectivity creates inputs and outputs with smaller capacities that can stagnate or choke off system flows.

Efficiency works in the opposite manner. The numbers of pathways are less but can handle greater volumes of inputs and outputs. Overly efficient systems are subject to brittleness and fragility, as even small disruptions can have major impacts. This is clearly 
seen in today's fiat currencies where billions of dollars, yen, euros and the like are exchanged daily throughout the world.

Sustainable system flows find a balance between efficiency and resilience. However, system flows universally find this balance asymmetrically and lean towards greater diversity and interconnectivity as seen in figure 1,

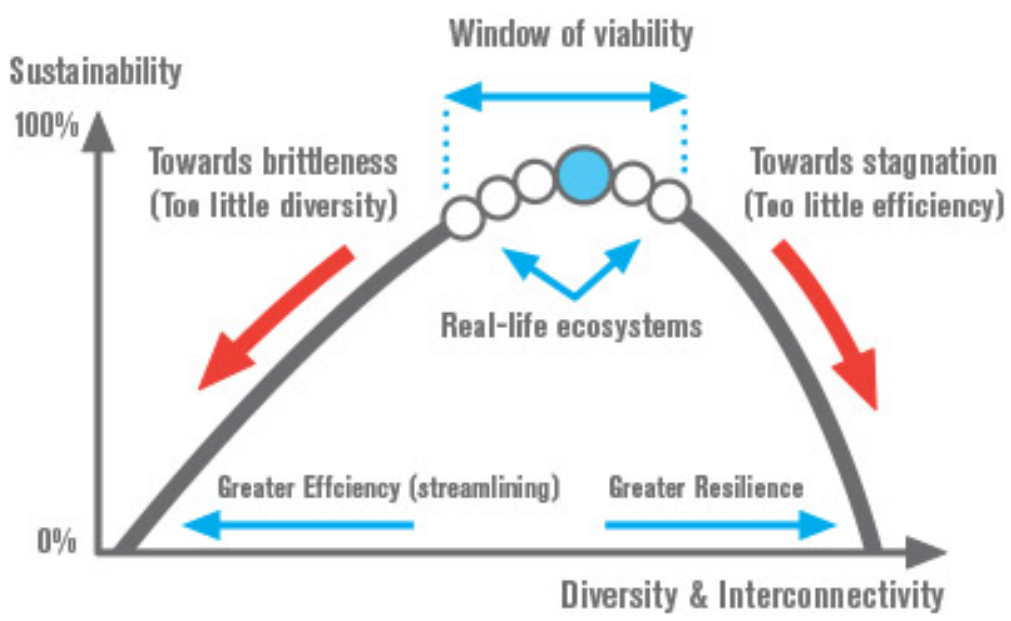

Figure 1: Balance between efficiency and resilience (Lietaer et al., p. 8)

Economies are no different. They too are system flow networks that connect millions of businesses to billions of consumers resulting in trillions of commercial transactions. (Lietaer et. al, p. 7) In times of economic downturn, blockages occur as consumers stop spending and begin saving money. The more severe a downturn the greater such blockages are. And because we live in a monoculture of currencies that are overly efficient, there are only a handful of mediums of exchange that can circumvent those blockages and mitigate the disruption of supply with demand at a regional level and none that work at a global level. Therefore, CCs play a potentially important role in 
providing businesses and communities with increased options for exchange, especially in conditions of economic uncertainty.

\section{CTE ATTITUDES AND MOTIVATIONS}

CTEs have been shown to be the most effective type of CC to support SMEs and therefore the have the greatest potential for economic development. Greco devotes an entire chapter to their potential, highlighting their cashless payment structure and interestfree lines of credit as their most important features (2008, Chapter 15). SMEs use these features when liquidity is in low supply as it gives them greater resilience during financial difficulties and also helps when expanding their business in good economic climates. In addition, my readings on the Wir's 80-plus years of existence, 80,000 business members, and regional reach as talked about in typologies was the concrete example that proved most persuasive. It is the largest of all CCs and is anchored to the Swiss Franc but is not exchangeable for it. (Stodder, 2009) It focuses primarily on SMEs and offers starting lines of credit of 10,000 in Wir credits. In 2012 it generated 1.46 billion in turnover in Wir credits. (De la Rosa \& Stodder, 121) It also possesses additional value that other CTEs do not in that it is also a B2C (business-to-consumer) CTE and offers savings accounts, financing, and as of late 2017 a 100 percent digital pension. (Wir, 2018. b). No other CC to my knowledge combines this amount of turnover and range of features.

Yet CTEs are different from other types of CCs in important ways. CTE members are primarily SMEs and their interactions are B2B (business-to-business). In addition, 
they tend to focus at the retail level. ${ }^{11}$ (Cresti, 2005) They are often service-oriented and favor businesses with higher margins of profit as there are significant transactions fees associated with their use. This is in contrast to their community currency siblings who are non-business based or a hybrid of $\mathrm{B} 2 \mathrm{~B}, \mathrm{C} 2 \mathrm{~B}$, and tend to give discounts to their users.

The attitudes and motivations of CTEs and their users has not been explored, especially compared with other types of CCs. I was curious to know if their differences made CTEs any more or less socially and or eco-justice based. Much has been written about community currencies especially LETS ${ }^{12}$ but I only found one paper that focused specifically and in detail on attitudes and motivations. In his paper, Ed Collom (2007) discusses timebank attitudes and motivation within the USA and concludes their members motivated to join out of needs or value-based reasons and were politically liberal. I found fewer papers written on CTEs and what they said generally only allowed me to infer their member's attitudes and motivations. For example, the Wir bank has a cooperative legal structure, which gives an indication that its likely a socially-driven enterprise. (Labour Business, 2013) However, I could find nothing specific about the attitudes and motivations of its users.

11. Cresti places CTEs into retail and corporate categories. Retail CTEs deal with small and medium businesses while corporate large ones. Methods of payment are also more numerous and sophisticated in corporate CTEs. Payment types include, clearing arrangements, switch trading, buyback, counterpurchase, and offset. (Hennart, 244) In comparison, retail CTE transactions are straightforward. For the purpose of this paper, when discussing CTEs I am always referring to those that are retail unless otherwise noted.

12. From 1997-2005 the International Journal of Community Currency Research alone has over a dozen papers on LETS systems from around the globe. They can be viewed at https://ijccr.net/pastissues/ 
One of the few documented examples is the Sardex, a for-social-benefit ${ }^{13} \mathrm{Ltd}_{\text {. }}$ CTE in Sardinia, Italy. (Littera, p. 8) A limited but insightful paper described the attitudes and motivations of both its founders and members. It was started in 2009 as a response to the GFC and has helped found the Commercial Credit Circuits, a network of CTEs based on the Sardex model. (Sardex) Giuseppe Littera et. al. describes its founders as purposedriven and coming from a social justice perspective. However, they clearly understand the Sardex must be a business that meets the economic needs of its members in order to succeed (its success is a testament to the balancing of both). It operates similar to many CTEs whereby it is B2B, has a closed currency that is non-exchangeable, and actively works to connect through marketing and sales brokers unmet demand with the unused supply of its members. ${ }^{14}$ As for its members, Giuseppe Littera et. al discusses the highly individualistic nature of Sardinians "that are comprised of close-knit family networks that do not foster generalized trust." (Littera et. al., p. 15) Their suspicions were a barrier to Sardex's adoption in its early stages of development. However, Sardex's role as mediator (the term broker is most used by US CTEs) between transactions eventually changed this and has since created a truly integrated robust community of businesses (it should be noted that this mediating/brokering feature is standard for CTEs).

13. I was not able to find information as to what constitutes a for-social-benefit corporation in Sardinia. However, it is likely to be quite similar to a for-benefit enterprises in the USA which is a hybrid of for-profit and nonprofit. Their fiduciary duty for a for-benefit is socially purpose-driven and they stress inclusive ownership, stakeholder governance, and fair compensation. (Sabeti, 2011) More information can be found at https://www.fourthsector.org/for-benefit-enterprise.

14. Data obtained from 2010 to 2014 shows Sardex has grown considerably. Membership in 2010 tallied at 237 with 402 transactions worth $€ 304,366$. In 2014, membership grew to 2,550 with 75,723 transactions worth €35,545,937. (Littera et. al., pg. 13) 
Again, the literature on CTEs is scarce and what does exist details their economic properties rather than specific attitudes and motivations associated with them. From Stodder's economic analysis of the Wir, I could infer the motivation behind its use was economic. Especially around its countercyclical effects that mitigate economic downturns (Stodder 2009). North (2010), Lietaer and Belgin (2010), and Greco (2008) all talk about this benefit in their books but their treatment is superficial in comparison. Marvasti and Smyth (1998) look at the underlying economic motivations behind trade exchanges and conclude their drivers are different. They assert that users of corporate trade exchanges (CorTE) (a type of CTE that deals with larger businesses that are not retail) are used when large corporations have high inventory and the use of smaller CTEs by SMEs are driven by high inflation. Cresti's analysis of the data comes to a slightly different conclusion than Stodder's. She agrees that CorTEs are countercyclical but sees CTEs, over the long run, are pro-cyclical and used to increase profits and not to mitigate economic downturns. (2005)

\section{SUMMARY}

CCs are diverse in nature and are designed to meet specific economic and social needs of the population that use them. CTEs have played a part in the economic health of SMEs for decades as evidenced by the Wir and their growth in the USA over the past 45 years. However, our understanding of them, specifically regarding the motivations and attitudes behind their use, has not been significantly examined. In fact, much that we know and can infer about CTEs comes from their community currency siblings. Nonetheless, we can still contextualize them within the literature as part of economic waves that call for a 
focus on business retention, alternative lending, import substitution and other selfreliance strategies that promote resilience.

In addition, despite the lack of research, we can reasonably infer that some of their motivations come from their economic benefits such as the ability to supply liquidity when credit is dry and additional marketing and advertising. However, the attitudes that are formed around such motivations are unknown. More nuanced attitudes and motivations regarding social and environmental justice are unknown as well. Theses underlying attitudes, motivations, and benefits need to be understood if CTEs are to be seriously considered as part of local economic development planning for the resilience and growth of SMEs. 


\section{METHODOLOGY}

\section{RESEARCH QUESTIONS AND EXPECTED FINDINGS}

The purpose of my research is to understand the underlying attitudes, motivations and benefits that are behind the offering and use of a CTE. These include both economic and psychological benefits. Obvious economic benefits would be but not limited to the lessening of excess capacity and increased revenue. Psychological benefits would be, but not limited to, a deeper sense of community and a greater awareness regarding social and environmental justice issues. A key economic benefit I was interested in was whether or not BizX mitigated the economic effects of an economic disruption and if so, how. I was also interested in what types of philosophical or political leanings BizX and its members had for the offering and use of the currency.

My expected findings were that BizX acted as an economic fallback during economic disruptions by providing liquidity to businesses when in short supply. Of notable interest was to see if this was especially so during the GFC of 2008 and 2009. In addition, I also hypothesized that BizX and its members were driven to offer and use the currency out of sense of community and larger social benefit as community currencies are known to do.

\section{CASE SELECTION: WHY BIZX?}

BizX is a privately-held B2B CTE whose main membership network lies in Seattle and the Bay Area. However, it also extends into Mexico, Dubai, and has a smattering of 
members in Canada, Europe and Asia. (BizX, a) It also offers 40,000 affiliates worldwide to which it can market a member's products and services. BizX is more than just an offeror of a currency and has other functions as well. Primarily a B2B currency, as a medium of exchange its main selling proposition is its ability to connect a business's unused capacity with the unmet demand of another business seeking its products and services. It does this through an online marketplace that hosts a myriad of businesses most of them service oriented. ${ }^{15}$ Businesses include: dental, chiropractic, restaurants; construction, advertising, information technology, automotive, travel and entertainment and many others. (BizX, a) In addition, BizX is more than a ledger of businesses as it takes a proactive approach to generating economic activity among its members. Upon signing up with BizX, each member is assigned an account representative who actively works to match their business within the network that have excess supply and unmet demand. (BizX, b) They do this with regular phone and email promotions and offer many other incentives and perks to its members. (BizX Interview, November 2016)

There were significant advantages and only a few drawbacks associated with the selection of BizX. Initial research into currencies of interest showed the most successful were either in Europe or on the East Coast. This posed significant difficulties not only because of distance but in the case of Europe, the likelihood of language barriers. Further research directed towards the West Coast revealed BizX. This was somewhat surprising to me as preliminary research on West Coast CCs had pointed to the Bay Area as a hotbed of activity. Organizations such as Bay Bucks with a network of over 200

15. Service industries tend to do better with BizX as their profit margins are higher than productbased ones. I discuss this further in my findings. 
businesses were stimulating commerce with SMEs in San Francisco In addition, think tanks like the Sustainable Economies Law Center in Oakland, which proactively promote cooperatives, grassroots finance, and other new economy initiatives, were discussing monetary policy. It was towards the end of my West Coast research that I found BizX in addition to Cascadia Dollars and some other smaller grassroots CCs.

BizX met the criteria for my thesis in that it neatly fell under Seyfang and Longhursts' definition of a CTE as described in the literature review. In addition, it was (at the time of my research) in existence for 14 years giving it more than enough longevity needed to evaluate it. Also, its proximity (three hours by car) made it relatively easy to do interviews (I lived in Portland). I was also impressed by its marketing. Most of the smaller currencies not only looked "grassroots" but had poor messaging, outdated information, and limited offerings. BizX was the opposite. Its marketing was welldeveloped as evidenced by their well-designed website, which clearly and professionally conveyed content and a special event I attended (I discuss this later) where the experiential design was well conceived and executed. Of even greater value was that it has an online marketplace with review features, a "Perks" program to reward employees of BizX businesses, and a sophisticated marketing and brokering department to generate and facilitate commercial transactions. In short, BizX was vibrant, successful, and technologically up-to-date like the community currencies in Europe and on the East Coast. In addition, its users stretched along the entire West Coast with international operations in Mexico and Dubai which potentially allowed for broader geographic 
insights. Except for the Regiogeld in Germany and the Wir in Switzerland no other CC I had read about was as regional in scope. ${ }^{16}$

\section{DATA GATHERING METHODS}

I took a qualitative approach to my research, interviewing 15 individuals, including ten BizX members, four BizX employees and one with a CC expert for background. This approach proved excellent at teasing out the nuances that were often part of the interviewees' attitudes and motivations. A sudden pause or wavering of the voice might reveal a subtext that would open the door for further inquiry or a point of commonality that would help establish a stronger rapport. I found the members who were initially the hardest connect with were often, ironically, the ones who were willing to share the most. One of my questions was about the percentage of the sales a member did in the BizX currency. To my surprise, in addition to the percentage, some would also tell me their amount of yearly sales. In one instance, a member admitted to breaking BizX rules of conduct which I discuss later. Though there were often mixed feelings about BizX there was only one member interview whose assessment of it was completely negative.

I began my project by reviewing the BizX website to identify members listed in their online market directory. From there, I developed a sample of 39 businesses based on the various business sectors represented on the BizX online marketplace. (BizX, f), In

16. The word region is an elastic term. It can encompass several states or an area smaller than less than 50 sq. mi. The Regiogeld is used throughout Germany and the Wir is used throughout Switzerland. Germany is slightly smaller than Montana and is approximately 134,835 sq. mi (Nation Master, a) while Switzerland is less than twice the size of New Jersey at 15,355 sq. mi. (Nation Master, b) (In comparison the size of the USA is 3,536,695 sq. mi. (Nation Master, c)) When I talk about regions I'm referring to a demographic size of roughly Montana which is 147,046 sq. mi. (City Data) 
addition to these sectors, I also looked at their location and the date they joined BizX.

From there I used the Mergent Online database to build company profiles that looked at when it was founded, the number of employees, and the amount of sales. I used this dataset as my primary sample for the ten BizX member interviews which I discuss in detail below.

\begin{tabular}{|c|c|c|c|c|c|}
\hline & SEGTOR & LOCATION & TIME JOINED & $\begin{array}{c}\text { NO. } \\
\text { EMPLOYEES }\end{array}$ & GENDER \\
\hline BUS. 1 & Car Repair & Bay Area & After 2009 & 5 & Male \\
\hline BUS. 2 & $\begin{array}{l}\text { Computer } \\
\text { Services }\end{array}$ & Bay Area & After 2009 & 33 & Male \\
\hline BUS. 3 & Restaurant & Greater Seattle & After 2009 & 32 & Male \\
\hline BUS. 4 & Restaurant & Greater Seattle & After 2009 & 10 & Female \\
\hline BUS. 5 & Bakery & Bay Area & After 2009 & 6 & Male \\
\hline BuS. 6 & Restaurant & Bay Area & After 2009 & 7 & Female \\
\hline BUS. 7 & $\begin{array}{c}\text { Building } \\
\text { Maintenance } \\
\text { Services }\end{array}$ & Bay Area & Before 2009 & 6 & Male \\
\hline BUS. 8 & $\begin{array}{c}\text { Building } \\
\text { Maintenance } \\
\text { Services }\end{array}$ & Greater Seattle & After 2009 & 5 & Male \\
\hline BUS. 9 & Media & Northern Oregon & Before 2009 & 2 & Male \\
\hline BUS. 10 & Law & Greater Seattle & Before 2009 & 1 & Male \\
\hline
\end{tabular}

Table 2: Breakdown of businesses interviewed (I have kept geographic and date statistics general to ensure the confidentiality of interviewees) 
Since BizX has been in existence since 2002 I was able to speak with businesses who became members between 2003 and 2015. This timeframe I hoped would yield insights into how BizX benefited them pre-GFC, during the GFC, and post-GFC. Interviews were done in person, through phone, and video conferencing. Sadly, international research was not conducted because IRB regulations would have required a board review that would have significantly delayed the start of the project. However, in addition to Seattle and San Francisco research subjects in Oakland, Berkeley and Oregon, were also interviewed. They ranged from 20-50 minutes in length with a combination of initial and follow-up questions. As I was interested in underlying attitudes and motivations of its members I inquired into possible philosophical or political reasons as to their use and what types of relationships were generated by the use of BizX. I also inquired into its economic benefits such as if it helped increase sales or weather a financial disruption. Additionally, I wanted to know if there were any challenges or limitations that were of notable value.

Interview subjects were first contacted via email. If an interview was agreed to then the appropriate IRB disclosure information was given with sufficient time to review before the interview. In addition to taking notes, I used a digital sound recording device for all but one of the interviews. This proved immensely valuable for ensuring accuracy and for help in reconstructing some of the interviews I highlight later on.

\section{- BizX Employee Interviews -}

I conducted a total of seven interviews with four BizX employees between November 2016 and September 2017 (see appendix 2 for questions). I also did one interview with a 
former BizX employee who was also a member. Conducting interviews with BizX management was key to my research as some had been with the company since it began in 2002. As such, their history would reveal valuable insights into the company's attitudes and motivations behind its establishment. My committee chair suggested starting out with staff could generate insights that would make for a richer interview with management so I decided to work my way up the organization. While still refining my research proposal I secured a preliminary agreement with a BizX account representative in late February 2016 to cooperate in the study. By early October 2016 my research proposal had been approved by my committee and the IRB however, at the onset of my investigation, the representative failed to respond to my interview requests. This threw me into notable distress as the process of finding another suitable research subject would have significantly delayed the start of my project. Additional detective work paid off when another account representative I contacted put me in touch with an individual in upper management. The phone interview I had with him was of immense value and paved the way for three additional interviews with BizX management.

Unfortunately, my poking seemed to arouse some suspicion and when I went for a follow-up with a mid-level manager I was told it had to be cleared by upper management. In addition, requests for a breakdown of their membership by sector were unsuccessful as was sales information that could have corroborated BizX's countercyclical effect. Despite these setback, my relations remained cordial with BizX. I completed two follow-up interviews with one executive however, it primarily pertained to historical background information on the company. 
I pondered briefly how to overcome this but wound up not having to concern myself. An interview I did the next day with one the members revealed she had been a BizX account representative several years back and I was able to acquire insightful data. Though procuring BizX employee interviews took a fair amount of effort finding their members proved much more laborious.

\section{- Member Interviews -}

BizX members were recruited through two avenues. The first was direct contact at BizX's annual 2016 Christmas party, to which I was kindly invited by BizX senior executive Stephen Hanson (named changed for confidentiality) after interviewing him at the BizX

offices. A lively event, which I estimated in size to be around 600 current and prospective members, was staged at a swanky bar in downtown Bellevue, Washington. It contained an impressive spread of food, prizes, hosted bar, DJ, musicians, and an aerial dancer to round out the entertainment all of which was paid for by BizX through BizX dollars.

This reconnaissance provided helpful background information and led to five (unsuccessful) recruitments. In addition, it revealed insights into the types of businesses that were BizX members. They were unpretentious small and medium-sized business owners engaging in a mixture of networking and holiday conviviality with Mr. Hanson greeting attendants as they streamed in. Roughly one-third of the people I interacted with were prospective members brought by friends or colleagues and looking for ways to market their company. Others were there simply to enjoy the night's festivities and all the members I met were based in the Seattle area. 
In addition to this face-to-face recruitment, businesses were identified through BizX's online business listing. 39 businesses out of around 2,000 listed on the BizX online marketplace were selected and ten of which were interviewed. My informal conversations with 17 people at the Christmas party and their responses were fairly consistent. I thought this might be because of the party. That perhaps it was only drawing people who were there to seriously network. However, my interviews were consistent with my informal conversations and I determined I had reached saturation after ten of them (see appendix 3 for questions).

Similar to other business listings such as Yelp, BizX members on the BizX online marketplace are rated by the users by the quality of their goods and services. Most of the companies listed were not rated and I selected a mixture of those that were and were not. This was done to minimize bias in favor of businesses who had favorable results with their transaction. I also combed through reviews of the BizX from local business listing websites and tried contacting their writers however, none responded. The members who I interviewed fell into the sectors of: restaurants, legal services, information technology, building maintenance, auto repair, and media. Other industries that were selected but were not interviewed fell into: skincare, medical, marketing and events, theatre, education, and hospitality. In addition, I interviewed a mixture of longtime and recent members from the years 2003-2015 to acquire a broad cross section of experience. 


\section{BIZX HISTORY AND BACKROUND}

BizX was founded in 2002 by the Canadian entrepreneur Bob Bagga and his friends Chris Haddawy, and Raj Kapoor. However, the roots of BizX are in large part tied to Mr. Bagga because of his previous decade worth of experience creating two other successful CTEs. (Matthews, 2017)

In 1992, after borrowing $\$ 10,000$, Bagga started Barter Business Exchange his first CTE. (Matthews, 2017) Some initial press acted as a springboard and by 1999 it had grown to 6,000 businesses across Canada with members such as Revlon, Kodak, and Rogers Broadcasting. (Matthews, 2017) "We were lucky. We were in the right business in the right time," said Bagga. (Matthews, 2017) As a result, Bagga purchased International Barter Corporation, a Seattle based CTE, and merged the two companies in April of 1998 which became Ubarter.com. It went public on the NASDAQ and by the end of the year was sold to Network Commerce for $\$ 45$ million who then renamed it Shopnow.com. (Matthews, 2017)

Two years later, Bagga, Haddawy, \& Kapoor started BizX off with $\$ 65,000$ and a modest goal of 500 businesses. As of 2017, BizX has a network of 5,000 businesses and has grown to a company of 40 employees, $\$ 100$ million worth of transactions, and nearly $\$ 13$ million in revenue. (Matthews, 2017) They also have offices in Bellevue, San Francisco, San Diego, and Dubai and have mostly SMEs as members. However, they also work with large companies such as Dell, Holiday Inn Express, American Red Cross and the San Francisco 49ers. (Matthews, 2017) 


\section{BUSINESS OPERATION}

\section{- Business Model -}

Membership is based on a three-tier pricing platform with that allows businesses to optimize its use (see figure 2). Notable differences in the plans fees decreasing from 7.5 to 6.0 percent, initiation fees range from $\$ 0$ to $\$ 395$ per month depending on the tier of usage. In addition, BizX behaves as a central bank because of its ability to inject liquidity into the network by creating interest-free loans ranging from $\$ 2,500$ to as high as $\$ 100,000$. Furthermore, it is a payment gateway because all business is transacted through its own digital payment infrastructure.

The BizX dollar is pegged to the U.S. dollar (inflationary pressures, which are discussed later, decrease this parity) and can only be spent within the BizX network. All transactions are taxable and BizX automatically reports sales to the Internal Revenue Service. (BizX, c) BizX boasts 340 million in new sales for members, 308 million in cash savings, and 680 million in transactions between its members. (BizX, d) 


ENTREPRENEUR
Initiation: Free
No Montly Fees
7.5\% Transaction Fees
Perks Employee Incentive
Online Marketplace
Up to 10 listings
at any time
60 day Trial Period

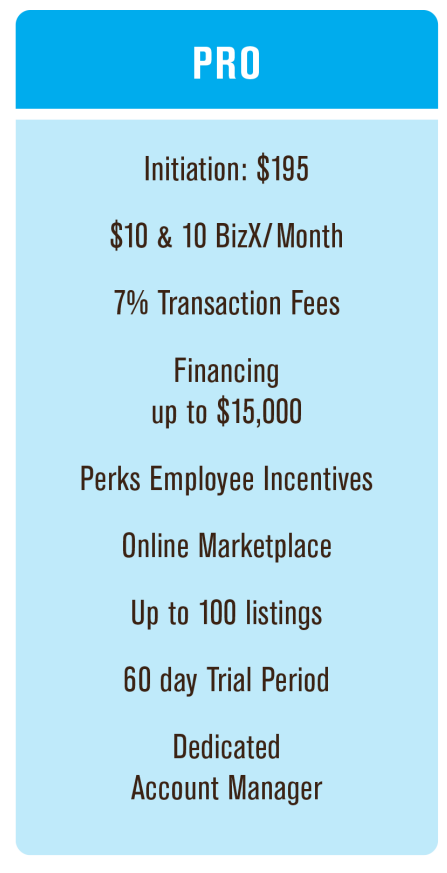

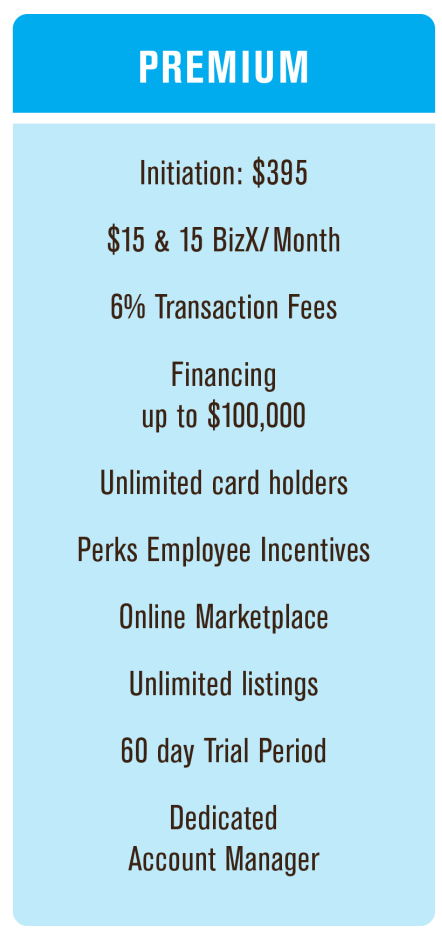

Figure 2: BizX's three tier pricing platform

\section{- Technological Choices -}

Many community currencies, have traditionally used either paper notes or checks as the medium of exchange. BizX from its inception has always been a digital. This has precluded the difficulties that are inherit in paper money such as counterfeiting. "If someone steals BizX dollars we own both sides so we can just reverse it.," said senior executive Bill Smith (not his real name) who worked on BizX's technology systems. Another benefit is that there is no need to refresh the supply of retiring bills. Additionally, digital transactions are inherently more convenient and most importantly, trackable. If it were a physical currency, BizX would have to rely on the good will of businesses to report sales that were not brokered and the ability to accurately measure its velocity and monitor other economic indicators such as industry usage would be difficult. 
This also makes logistical sense as the BizX currency works at a local, interstate, and international scale and issuing and tracking BizX notes would add additional complexity.

\section{- A Broader Vision -}

In my interviews with Smith and Hanson both talked of larger visions for BizX.

Traditionally it has functioned as B2B currency however, within the past three years it introduced its Perks program that has technically made it a B2C currency. Perks allows employers to give a portion of their BizX dollars to employees as bonuses or even as partial payment for their labor. (BizX, e) In addition, there are strategies being discussed for significantly greater adoption of BizX that could make it one of the most widely used currencies. However, neither would elaborate.

Nonetheless, both Smith and Hanson shared some plans whereby BizX would operate on a national scale addressing excess capacity issues. Smith specifically spoke about how the U.S.A.'s gross domestic product was 14.6 trillion and that out of it 24.6 percent or around 3.5 trillion was in waste or excess capacity. If BizX could decrease businesses excess capacity by one-half percent it would increase BizX's revenue to 40 billion dollars a year if we apply BizX's commission fee of 12 percent and 50 billion if we apply its 15 percent. Such a vision is ambitious but not impossible.

Though BizX has promoted itself as a community currency and actively works with charitable causes by allowing BizX donations to be made to them, it its main value proposition is economic. In addition, it is apolitical in nature and does not actively advocate any social or environmental justice agenda. However, senior management is motivated by set of values that are socially conscious and are articulated by its manifesto 
which is discussed in my findings. However, these values were not reflected by its members as their prime motivation nor value. 


\section{FINDINGS}

\section{MOTIVATIONS AND ATTITUDES}

Why do businesses use complementary currencies (CCs) like BizX? Some like service credits are largely driven by notions of social or ecological justice while others like LETS emphasize a mixture of community building and commerce. Even local currencies whose purpose is economic still inspire a sense of placemaking and regional pride. This is quite different than that of CTEs which are primarily concerned with apolitical trade.

Though BizX markets the benefits and importance of community it does so entirely from an economic perspective. There is no mention of social or environmental justice or talk of monetary reform in its marketing materials and Hanson confirmed that BizX steers away from political affiliations. However, as an entrepreneur he clearly states his embrace of capitalism and is a proponent of free trade. Smith echoes this saying, "there is nothing wrong with profit." When asked about if BizX has any aspirations to play an activist role in monetary policy outside its own currency, Smith clearly stated that he had no interest in seeing BizX fight the financial and monetary hegemony that banks have and which currencies like the Lewes Pound indirectly attempt to mitigate through their strict localization of money. He sees the most benefit BizX offers is the diminishment of excess capacity and technology as an important tool to do this. In addition, he finds most other fintech companies have frivolous offerings or merely 
breakup ${ }^{17}$ products that are currently done by banks. Furthermore, he states that BizX differentiates itself from other companies like Groupon who liquidate excess supply through severe discounting because of BizX's ability to create customer loyalty through its business community. However, Hanson and Smith say that at the heart of BizX is a commitment to the building of hyper-local economies. BizX, as both see it, creates social good from the rising economic prosperity of a community through leveraging the network of its members. Its concise and aspirational "manifesto" states:

BizX is more than a company. BizX is an idea and a network. A gathering of smart business owners with a common purpose - to upgrade their businesses and lives through the power of trade. The BizX team exists to fuel that trade, to enable businesses like yours to unlock their full potential. BizX is a collaboration.

BizX is more than a currency. The BizX dollar contains the blood and sweat, the aspirations and successes of thousands of entrepreneurs like you. Through this trusted currency, otherwise empty seats, un-billed hours, and empty billboards, are transformed into things you want and need. BizX is concrete value.

BizX cannot be owned. BizX belongs to its members, each leveraging the strength of this vast network of like-minded networkers, working

17. An example would be the payment app Venmo which uses existing banking architecture to help people make cashless transactions to each other. Another is PayPal which is mostly a payment gateway. Though BizX offers credit like a bank and is also a payment gateway it is different in that it controls its own currency. In addition, its brokering service connects unmet demand with unused supply in a way that banks do not. 
successfully against the odds and thriving. BizX members understand the power of collective, the volume of the crowd, the opportunities in the

Sharing Economy. BizX is your economy.

We are greater than the sum of our parts. We are in this together, for each other. We are the business of community.

We are BizX. (BizX, b)

Clearly though BizX's main focus is economic there is nonetheless a social mindedness which falls in-line with other community currencies. This is seen in part by Hanson's commitment to build a "purpose-driven" company that will improve people's lives." He attributes the book "Good to Great" by Jim Collins as a source of inspiration and guidance in doing so. "If you fulfill the economic need you fulfill the social need," Hanson asserts while concluding that "rising tides (economic prosperity) lifts all boats." This social mindedness is also evidenced by Hanson's plans to make BizX a certified B Corp (it is currently only a LLC).

\section{- Member Motivations and Attitudes -}

Member motivations where largely in line with Hanson's. The ten businesses I interviewed expressed a range of them however they were all mainly economic. None said their prime reason for using BizX was a connection to community, business or otherwise as in the case of community currencies. It was first and foremost a tool to help them financially. However, three did attribute that their joining was in some small measure out of BizX's emphasis on a local business community and personal perception 
of social-consciousness and even nostalgia. Dingo, a baker (it should be noted that all names of members have been changed for confidentiality), loosely associated BizX with socialist ideology whereby he quoted Karl Marx, "From each according to his ability, to each according to his needs...If someone can create their thing and I can create mine then we can trade with each other." He was not able articulate this motivation in greater clarity but it was evident he saw BizX as a way to maximize his productivity while still transacting in a way he felt was socially-conscious. Another member, Bernard, incorporated a sense of nostalgia, "It's the old system (bartering). It's the way things were done hundreds of years ago... If you read through your history a lot of things were done through trading labor." 18 He added, "It's a more straightforward (way of doing business). And besides, screw the government...we're a country with way too many laws on the books and way too many taxes and it doesn't need to be like that... BizX has this idea and that's why I love doing business with BizX." ${ }^{19}$ Only one member in Seattle, Jay-Jay, experienced a notable degree of community despite doing only doing 3 percent of his total sales in BizX. "Ya, you do get to know them (other BizX members). Some of

18. Though people did trade labor Bernard's understanding of barter is historically limited. David Graeber in his book Debt: The First 5000 years debunks common economic thought that commerce started with barter, then coins, and finally credit systems. (2014) In fact, the opposite is true. This historical portrayal, Graeber explains, is in great degree attributed to the father of economics himself, Adam Smith. Smith, in his distaste for political institutions, asserted incorrectly that markets, money, and property preceded the formation of governments His assertion was that the act of trade was an organic process that happened spontaneously between individuals. However, the earliest anthropological evidence of early human economies dates back to 3,500 BC in Mesopotamia and shows clays tablets with cuneiform writing that were ledgers used for accounting. In addition, Graeber points out that these tablets were administered by priests and government bureaucrats. Graeber quotes British anthropologist, Caroline Humphrey who wrote the definitive work on barter and who says decisively, "No example of a barter economy, pure and simple, has ever been described, let along the emergence of it from money; all available ethnography suggests that there never has been such a thing." (2014, pg. 29)

19. Bernard did not seem to have a firm understanding of BizX's legal obligations to collecting taxes. All members pay sales tax on purchases and BizX, by law and practice, reports all sales to the IRS. 
them actually become friends and if they're not too far away you trade back and forth quite regularly. "But,' he said jokingly, it's not like we're doing secret handshakes." Despite the friendliness Jay-Jay experienced community was still a secondary benefit for him.

The other seven businesses saw their motivation as purely economic. To them it is primarily a way of connecting unmet demand with unused supply and expanding their customer base. "It's not that I'm not deep," said Charles laughing in jest, "but I see BizX as an alternative economy and not an alternative philosophy. It's very commercial. It's very grounded in capitalistic exchange.” Patel, a Bay Area member, who despite considering himself "leftwing" and living in a cohousing community, echoed the Seattle members sentiment saying it was entirely "practical" in nature and not based on his personal politics or a social justice philosophy. Swen, another Bay area member, mentioned that in addition to economic motives he also operated out of a sense of deep loyalty. "BizX has been very good to us. We could work with other barter companies (in addition to BizX) but we don't." This loyalty was in large part to the added value of BizX's brokering services and was also commented on by seven of the members. They found it especially useful when engaging in large and involved transactions.

Interestingly, four other businesses had worked with another CTE in the past but only two continued to do so. Finally, out of the two that continued, only one preferred doing business with the other CTE. 


\section{- Attitudes Towards Adoption -}

A challenge often faced is the abstract nature of a complementary currency. Money is something society in general takes for granted and as such is not well understood. "Funny money" is not an uncommon term to describe community currencies. Adoption takes time and with much preparation and stewardship. Even when a currency is operational acquiring ongoing adoption is challenging. This is to say nothing of the consumer marketing that took and continues to take place at a CTE such as BizX.

These approaches have been markedly more successful than many other community currencies who have emphasized placemaking and a sense of social justice. (This is not to say those approaches have not been successful but is merely an indication of the needs and wants of the community members who take part in it.)

Interestingly, Hanson asserted that despite its perceived complexities, many people will sign up for BizX if recommended by a friend or someone they know and will wrangle with its abstractions later. However, BizX understands that not every business is a good candidate for its community. Companies that have low fixed costs and high enough margins of profits that can absorb the total 12-15 percent in transaction fees are good candidates. Service companies like dentistry and chiropractors tend to do well however, those that sell low-margin products like electronics or clothing tend not to. (BizX Interview, 2016)

Out of the ten members interviewed, four confirmed that recommendations from associates and friends played a part in them signing up with BizX. Chang was motivated by the recommendation of a customer, "She really liked it so I signed up because of the benefits but I didn't understand it at first. I had a lot questions for the rep and she was 
good about making things clear. But I wasn't sure if it was legal at first." ${ }^{20}$ Jay-Jay signed up at the behest of his business partner. 'I'll be honest, I still don't totally get it. I let my partner take care of it really." "I was told about it from the guy who ran Bay Bucks (a mutual exchange in San Francisco)," said Swen. "I felt okay about using it. It wasn't difficult to understand." Interestingly, Tanisha first heard about it from a family member. "A family member told me about it and I later went to work (at BizX)...so I understand how it works from the inside."

Of the six that had been signed up by a BizX representative, three had previous experience using a CTE and did not report having problems understanding how it worked. Sasha, who owns a business maintenance company was approached and said, "The marketing part of it was easy but the money idea was a little weird. I wondered if it was a scam (laughing)." The rest of the members found the onboarding process relatively easy and their experience working with their representative was all but in one case positive. Members who had not worked previously with a CTE also reported having little to any trouble difficulty. "The rep was helpful in explaining it. I didn't have a problem," said one member. The two other members expressed similar sentiments.

20. Before becoming a member a consultation that clearly articulates its benefits and limitations is undertaken by a BizX representatives to ensure the right fit. Those without excess capacity and who are not looking to minimize costs will likely be a mismatch. Also, those who seek to spend their money on casual expenses are not seen as good prospects nor members who seek to convert their BizX readily to cash. 


\section{ECONOMIC BENEFITS}

When BizX members where asked about its economic benefits two said that it helped them through a financial hardship. Bernard, spoke of when his auto repair company moved from a two-bay facility to a twelve-bay he used BizX dollars to pay for movers. "It shortened a two-week moving period to three days and allowed us to stay close to capacity at our old garage during the entire time," he said happily. It also kept his work days manageable by precluding him to work late into the evenings and cut down on other capital costs.

Swen also reported that BizX modestly helped weather the GFC. "Clients weren't spending," he recalls, "so in 2008 we signed up and 48 hours later got paid 2,500 BizX dollars (BX) for a troubleshoot order.” In addition, he estimated that from 2009-2011 10-20 percent of his business was done through BizX. This is noteworthy as the effects of the GFC were still palpable for many businesses during that time. BizX also helped out during unexpected expenses. Jay-Jay had series of plumbing problems that costed upwards of $\$ 800$. He was often able to pay for over half of them with BizX. "Boy, (exhales loudly) that's when you're glad you have it (BizX)." He also mentioned BizX members have spent upwards of BX1,000 on events at his establishment.

BizX has also helped companies expand as well. Bernard, as a result of his move, has seen his business grow by at least 10 percent and expand it by a 500-mile radius. One member said that through BizX he is was able to spend BX30,000 in advertising (he plans to spend BX100,000 in 2018) and it is also allowing him to rent new office space. Other large expenses for members were personal such as BX30,000 for dentistry, 
BX5,000 for international travel and BX30,000 for advertising. Smaller purchases of less than BX100 were often for food/restaurants, sporting events, clothes, and printing.

Nearly all of the businesses interviewed reported that more than 3 percent of their sales were done in BizX, with the highest being 20 percent (see table 3.1 and 3.2 for a detailed breakdown). Because of BizX's cumulative fees between buyer and seller none of the members offered deals nor mentioned receiving any. The fees led to an inflationary effect that is discussed later. 


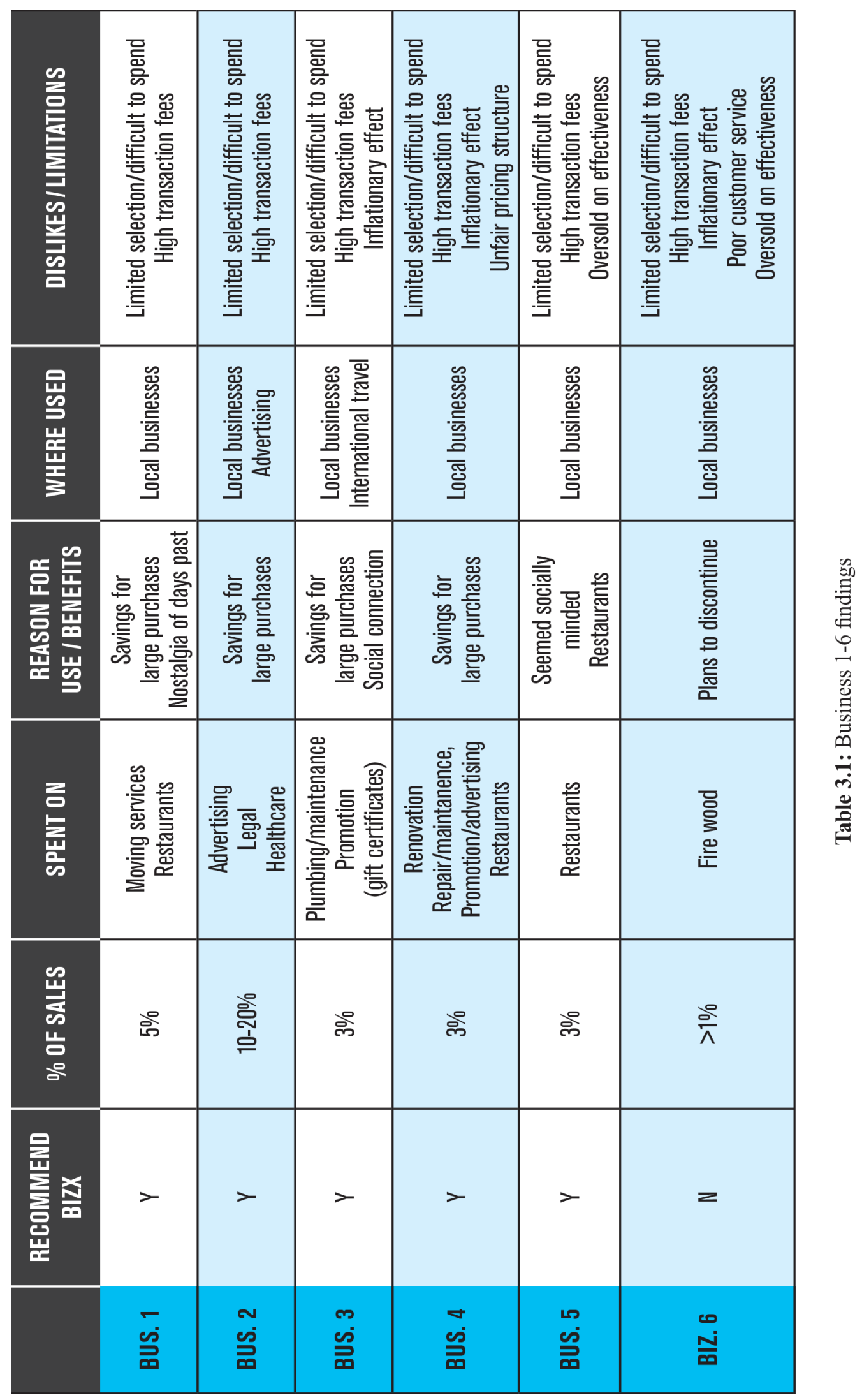




\begin{tabular}{|c|c|c|c|c|}
\hline 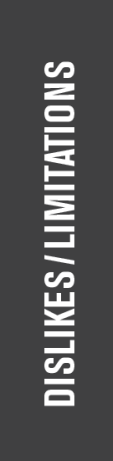 & 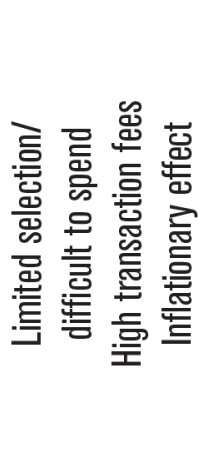 & 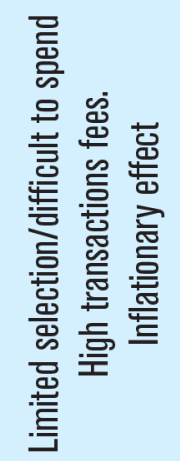 & 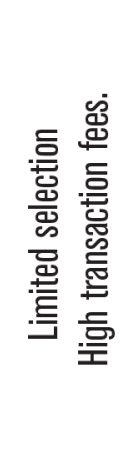 & 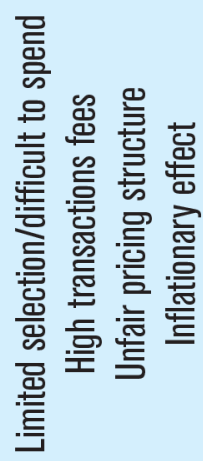 \\
\hline 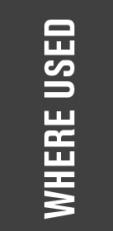 & 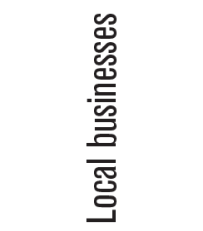 & 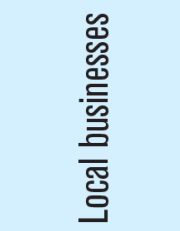 & 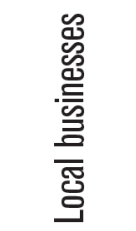 & 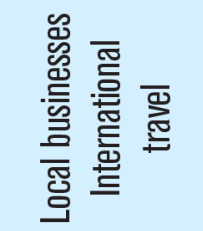 \\
\hline 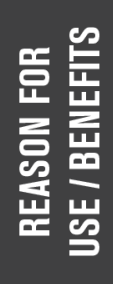 & 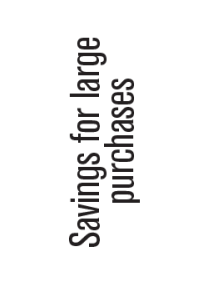 & 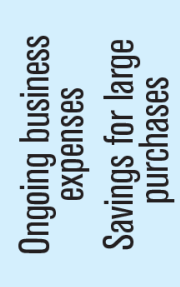 & 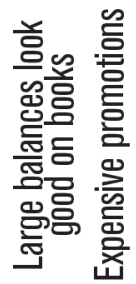 & 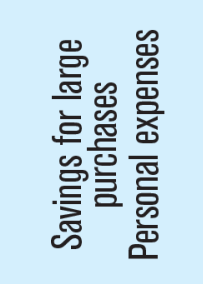 \\
\hline 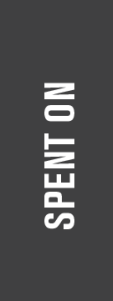 & 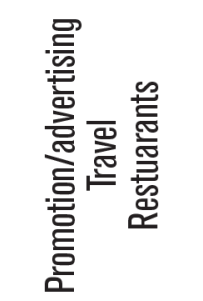 & 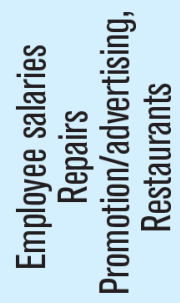 & 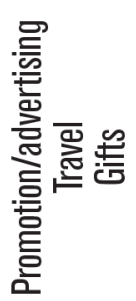 & 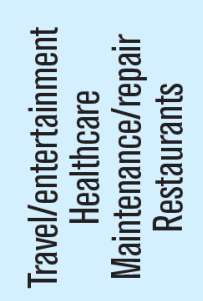 \\
\hline 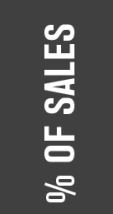 & $\begin{array}{l}\text { ते } \\
\wedge\end{array}$ & ते & 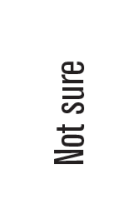 & ભે \\
\hline 呈 & $>$ & $>$ & $>$ & $>$ \\
\hline & 今 & $\begin{array}{l}\infty \\
\rho_{\infty}\end{array}$ & $\begin{array}{l}\text { ه } \\
\text { ळ }\end{array}$ & 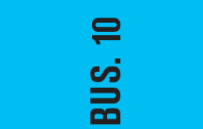 \\
\hline
\end{tabular}




\section{- Networking Value -}

BizX's networking ability via its marketing and brokering services were noted by most of the members interviewed to be one its best attributes, and all but two found the marketing and brokering service to be of value. And, out of those members only one said that despite his inability to spend BizX dollars, BizX representatives were still consistently informing him of possible opportunities and continually sending him customers. With advanced planning and use of BizX's brokers, members could more often than not find the quality products and services without the hassle of looking for them. "BizX has it right," said Robert. "They look out for you. They don't say, 'hey, you can do this and it'll only cost you this. They look to build your business. They look to putting the right people in touch with the right people. The right people who fit your need." This active networking was key for another member who had used another CTE. "They (the other CTE) just signed me up but never did anything for me.” For him, it was his account representative that connected him to what he considered its primary value. Despite BizX hosting various events (their annual Holiday party being their largest) only three of my interviews reported attended one and none reported a resulting purchase or sale. These members were also in Seattle and San Francisco which have robust networks.

\section{LIMITATIONS AND CHALLENGES}

While nearly all BizX members interviewed experienced benefits, they also identified a number of limitations and challenges to using it. One of the most common complaints among the BizX members were the inflation effects of the currency on its members pricing. Because BizX's commission fees devalue buying power by 12-15 percent, none 
of the businesses interviewed said they offer discounts they normally extend to cashpaying customers. In fact, BizX often has the opposite effect. One member admitted he inflated his prices $12-50$ percent depending on the product or service being purchased. Another charged his customers a $\$ 25$ fee to use BizX to not only offset costs but to increase revenue. "That's our way of having BizX generate capital," he said candidly. Another restauranteur, Alicia, illustrated some of the disparities with the cost of signage she was considering buying, "I'll get (cash) quotes from three companies and one is $\$ 10,000$ for example. And let's say another one is $\$ 11,000$ and another one is $\$ 9,000$. Then I look at the BizX price from another vendor for the same signage and it's $\$ 17,000$." She also reported this as so common that it had become best for her to pay cash for certain services that she could easily obtain through the BizX network. This is quite different than other community currencies that do not charge a commission and even give a discount to currency to users as a loyalty reward. It should be noted that BizX actively discourages these inflationary practices.

Another complaint is how the BizX commission was structured. Charles felt that the commission should only be based on the selling price. "Sometimes I will offer to pay a small business the sales tax in cash because I think it's fairer. I won't insist on using BizX." he said as a point of principle. Tanisha remodeled one of her establishments and disliked that the construction services brokered through BizX did not include supply costs. She perceived this as unfair since she could not deduct the cost of food supplies from the sale of her BizX transactions or get a lower commission fee in lieu of this disparity. "I don't like that aspect of being a member" she said emphatically. She also 
noted that none of her BizX customers ever converted to cash. ${ }^{21}$ Finally, she complained she was unable to write off the BizX's fees as her provided tax statement as BizX did not show their commission. Charles also expressed his dissatisfaction with pricing. "BizX is all over the place...It would be more robust if its commission were not based on the cost of sale but only the profit." 22

The three businesses that were not in close proximity to areas where the network was more robust, such as in Seattle and San Francisco, complained more of not being able to spend their BizX dollars and had large balances of BX6,000 and substantially above. However, even members within robust networks often complained of not having enough options to spend their BizX dollars and one member disclosed that in the past he had a balance of BX50,000. Often times he found BizX simply could not be used for many of his large business expenses. "Most of my business expenses are taxes and rent. This is also the case with smaller business purchases, I can't buy a printer (with BizX) because the profit margins are so low (for the seller)." He admitted to being "particular" and "idiosyncratic" about the things he buys. "I'm not interested in second choices," he clearly stated. Such "pickiness" has exacerbated BizX's limitations for him. "The quality of service (within the BizX network) is unpredictable and coincidental. The typical transaction on the spending side is there happens (italics mine) to be a particle vendor

\footnotetext{
21. Tanisha had hoped BizX would bring in BizX members who would eventually begin to pay for her products in fiat dollars. But in her case BizX members' loyalty was to the network. From my interview with Tanisha, I gathered they were looking for ways to spend down their large balances. And, had they not had them would have been less likely to patronize her establishment. Regardless, BizX held its value and brought her business she would likely not otherwise have had.

22. Charles' suggestion certainly seems to be more fair but would also be quite difficult to administer. For some members doing a detailed breakdown of inventory would prove difficult. In addition, such information would understandably be considered confidential and would not want to be shared.
} 
available for the particular thing you want." As a result, he estimated that 75 percent of his BizX purchases were for personal expenses and vacations.

This coincidence of needs is echoed by other members. One noted that paying with BizX was less convenient when retaining certain services because it was not uncommon for those services to be unavailable through the network or that they could not be paid in total with BizX. This was notably so with services that required a significant amount of supplies such as with construction or repair work. Nonetheless, he found with a certain amount of planning he could accomplish many of the things for which he would otherwise need cash for.

\section{CONCLUSION: SIGNIFICANT VALUE DESPITE LIMITATIONS}

\section{- Primary Value: Resilience and Growth -}

Despite BizX's limitations, all but one of the study's participants said they would continue to use it and recommend it to others. Because of limited spending ability in his area, Patel saw it as a "savings account." Interestingly, despite Tanisha's frustrations she looked at BizX's limited spending in a positive light. She likened her account to a forced "rainy day fund" that helped out during times when cash was tight. It is this "forced" savings effect where most BizX members found its greatest value. Because of the network size limitations — even where the network was robust — day-to-day purchases of desired products or services were not often possible for most of its members. But, BizX made significant differences when medium to large financial expenditures were necessary and when cash was in limited supply. BizX members were significantly able to grow their businesses or pay for the cost of repairs that they would otherwise have 
experienced difficulty in doing or would not have been able to do at all. None of the members mentioned using BizX credit to finance any expenses.

In addition to moving and constructions costs, costly advertising and promotional buys were cited an important part of their growth strategy for five of the businesses. Purchases as high as $\$ 30,000$ were reported and one business at the time of this writing is planning ad buys of BX100,000 for 2018. Jay-Jay had unexpected plumbing repairs that cost $\$ 800$ and roughly half of which he was able to pay via BizX. Finally, one member noted he paid BX150,000 for attorney services over a period of 10 years.

The payment of large personal expenses such as costly medical needs or expensive vacations were an important secondary benefit. To a smaller effect was its ability to be "gifted" by members who ran high balances to their employees via their Perks program or in the form of BizX gift cards to their customers/clients.

Finally, only to a small degree did members' attitudes and motivations reflect those of community currencies. The sense of placemaking and community driven by social and ecological justice ideologies were sparingly evidenced. Nonetheless, member attitudes and motivations were consistent with BizX's upper management purpose-driven mission of economic prosperity. 


\section{DISCUSSION}

\section{OVERVIEW}

My initial purpose of this paper was to gain insights into the attitudes and motivations behind, and benefits of the use of the BizX CC. My interest was to see if a CC barter network such as BizX would bear out my readings of many of the other types of CCs I studied. Did they approach it from a perspective of economic and or social/ecological justice and if so why? To what degree, if any, did they find it of value? And if so, what role could it play could it be within a larger urban studies framework of economic and community development?

My findings in large part were a mixed bag in relation to my stated hypotheses. Early readings led me to believe that the use of a $\mathrm{CC}$ was of most value when it was mitigating an economic disruption or in the creation of community. Evidence that BizX worked in counter-cyclical manner was given when a company manager indicated that BizX does better when economic times are at a downturn. ${ }^{23}$ This increased use supports BizX's resilience properties that are lauded by proponents of CCs and supported by Lietaer's system flow theory examined earlier in this paper's literature review. However, I thought members' use of BizX, especially during the GFC, would be more significant (I am certain a larger sample size would have likely revealed additional experiences with BizX's economic resilience properties).

23. Sadly, requests for sales data to corroborate this were unsuccessful. 
The most unexpected finding among its members was its significant value during average to good business climates. That BizX was often used to grow member businesses that didn't have the cash on hand to do so was unexpected. In addition, was its value for large personal expenditures such as medical and vacations. My early readings had me concluding that at most, from an economic perspective, a CC would be best used in contingency planning for economic development policy. It would be a fallback mechanism that would activate in a dismal economic period. However, my findings suggest that BizX, and CTEs like it, have enormous potential for proactive economic planning as well. As Smith noted, the excess capacity that businesses carry is significant. In 2017 alone US excess capacity averaged 24 percent. (Trading Economics). If such capacity could be reduced by a CTE by a few percentage points the economic impact would be in the tens of billions of dollars. As a result, local economies would become more competitive. In addition, the ability to procure interest-free or low-cost loans from a CTE, as in the case of the Wir, ${ }^{24}$ would lessen the grip of the today's financial regimes on liquidity and further increase the resilience of SMEs. But first, let us review some of the network findings and discuss their impacts.

24. The Wir offers a maximum interest rate of $1.75 \%$ is charged on WIR-mortgages. As for overdrafts, different interest rates apply depending on the user's collateral. For WIR overdrafts backed by accounts $1.5 \%$ is charged, $2.5 \%$ for other collateral (e.g. 2 nd mortgages) and $3.5 \%$ if no collateral is offered. (CCKG) 


\section{BIZX COMMUNITY AND ECONOMIC NETWORK LIMITATIONS}

\section{- Analysis of Community Network -}

Though BizX markets itself as a community currency it is, by this paper's and traditional academic definitions, clearly not. However, I do not think this is a dishonest attempt to market the company, as Hanson's experience with CTEs is as a practitioner of a particular subset of CCs and not a theoretician or academic viewing them holistically. Despite BizX's typology as defined by this paper, I wondered if that same sense of community building and placemaking might be as vibrant and shared as other community currencies. Early discussions with Mr. Hanson and his sincere emphasis on a sociallyminded and "purpose-driven" business suggested that this could be possible. However, the data collected indicates that this is unlikely. BizX's apolitical stance and clear focus on its economic benefits are what drives its members to use it. The early observations I made and conversations I had of BizX members and prospective members at the Christmas party I attended were consistent with the majority of my later interviews. They were there to network and find ways to strengthen their businesses and not to intentionally form a cohesive and deeply connected business community or otherwise. The very last line in the BizX manifesto says, "we are the business of community" and I argue that this is in part oversold. More than anything, an accurate description of BizX would be a collection of mostly-localized trading networks. The deeper social and emotional bonds and sense of placemaking that are the cornerstones of community currencies simply did not present themselves in a meaningful way in the data collected. 
My conclusion is that Hanson's goal of community, though truly genuine, is more aspirational in nature. Despite this, I do not see this limitation significantly diminishing its value as an economic development tool which I discuss shortly.

\section{- Analysis of Economic Network -}

It is clear from the interviews that a key area of frustration was the limitations of the BizX network. Despite the participation of 5,000 businesses, members still indicated that they could not find many of the goods and services as they wanted. They wanted more choices not just locally but also regionally, and in two cases, internationally. For the purpose of discussion, I differentiate trade done on a regional scale as intratrade and that done on an international scale as intertrade. When members wanted intratrade, they were looking to grow through the exportation of their services and wished to find media outlets for advertising or contractors for renovations of office space. When seeking intertrade, members were looking to vacation abroad. Expansion beyond their region is the obvious solution but there are strong arguments that oppose such expansion. Their validity is worth brief discussion as they have the potential of undercutting the very benefits for which they are used for and endangering the proliferation of CCs in general. Let us start with the reasons for. Proponents in favor of intertrade and countertrade between CTEs or even the expansion beyond a CTE's local network argue that: they strengthen organizations and supports the CC movement overall; can create larger markets for CCs own products and services; helps to create a "critical mass" or the amount and diversity of participants that makes CCs valuable; large networks can support trustworthiness and 
safety of a currency; a CC acquires more resources by sharing them. (Martignoli, 2015, p. 139)

Opposing arguments of intertrade and intratrade which come mainly from the traditional community currencies posit: intertrade will allow for the influx of bad investment; there are significant risks of unbalance and abuse; convenient interchange mediums already exist such as fiat currency; larger firms will cannibalize smaller firms thereby destroying diversity and bringing in "bad money;" greater risk of legal issues and judicial examinations especially at larger sizes; the watering down of a CC's original purpose which is often social equality and equity. (Martignoli, 2015, p. 139)

Some of these questions have already been examined and a deeper analysis of others is beyond the scope of this thesis but some can be addressed. If BizX and CTEs in general continue to grow will they crowd out or devour smaller community currencies and begin to injure the hyper-local economies they seek to serve? When asked how BizX's expanding the network could undermine the development of local economies through capital leakage, both Hanson and Smith believed the benefits would outweigh the negatives. Smith articulated the argument for BizX most clearly. He understands that large amounts of capital leakage in the sole form of cash could be deleterious to a local economy. However, in the case of BizX dollars, outflowing would still be offset by its gains. He gives a hypothetical example whereby a local economy has 100 million BizX dollars circulating throughout it. However, market forces create an outflow of BX80 million to another BizX community. There is still 20 million BizX dollars left in the former economy that it would not otherwise have. He goes on to say, "It's our core business belief we have to have one BizX dollar equal one U.S. dollar so if that big of an 
imbalance occurs, ...(it is) going to drop the value of the BizX dollar (in locations that experience a high inflow of BizX) and people are going to start over-charging and over here (in locations that experience a large outflow of BizX) people can't use it.” He continues, "It's not even in our interest to have excessive imbalance in money supply compared to the demand. We have to balance that both on a micro-level as well as on a macro-level across all our markets."

Regardless, the question of "how big is too big?" will be different for every community or region with which a CTE and/or a community currency operates in. However, perhaps the main question is not so much about size as it is type. In my opinion, an open currency like BizX, with its relatively agnostic stance to issues of social justice, is unlikely to deter or diminish the proliferation of community currencies whose main purpose is social/eco justice, equity, and placemaking. Such concerns were insignificant to the BizX members interviewed (at least in their use of the currency). For them, a larger and broader network would be greatly welcomed and likely help promote their resilience. If the aim is for maximum economic effect, as it is for BizX members, then a CTE's networks should be grown and expanded.

It must be kept in mind that a growing and expanding network would likely diminish BizX's benefit as a forced savings/rainy day fund as people would have more opportunities to spend their BizX dollars. However, the broader economic benefits through increased commerce, especially during downtimes, would more than make up for it. 


\section{CTES AND REGIONAL ECONOMIC DEVELOPMENT}

Despite BizX's limitations, it and CTEs in general hold enormous potential for the growth of regional economic development through supporting the resilience and growth of SMEs. Sadly, their value has been overlooked. As discussed in the literature review, general approaches to regional and community economic development has been to attract large corporations ${ }^{25}$ and offer sizable tax breaks, financial incentives, infrastructure creation and other benefits at the great expense of tax payers, workers, and unions. Such effects can be devastating especially when a significant portion of a local economy is dependent on the corporation's presence and it leaves in search of greener pastures. This is in sharp contrast to SMEs. They are not afforded the same incentives large corporations are and by their nature are embedded and heavily invested in the communities they serve. They simply cannot up and leave when economic times are in decline. Their size also makes them more vulnerable to market failures, barriers, commercial inefficiencies, and public policy decisions. (OECD, 5) It is also more difficult for them to access credit than larger firms especially in economic downturns. Despite all their challenges and disadvantages they experience they play an indispensable role in the world economy and are responsible for 70 percent of all jobs in the OECD zone which include Europe, the USA, Japan, Korea and countries in South American, the Middle East, and West Asia. (OECD, 4) When taking informal businesses into account they average 50 percent of jobs, between 50 percent and 60 percent of value added, and

25. It should be noted that SMEs are not completely cut off from capital as CDFIs do exist. However, funding is still limited worldwide. (OECD, 2017) 
account for 50 percent of GDP in most countries. (OECD, 6). The World Bank estimates that in developing countries in Asia and Sub Saharan African formal and informal SMEs make up as much as 60 percent of their GDP. (World Bank)

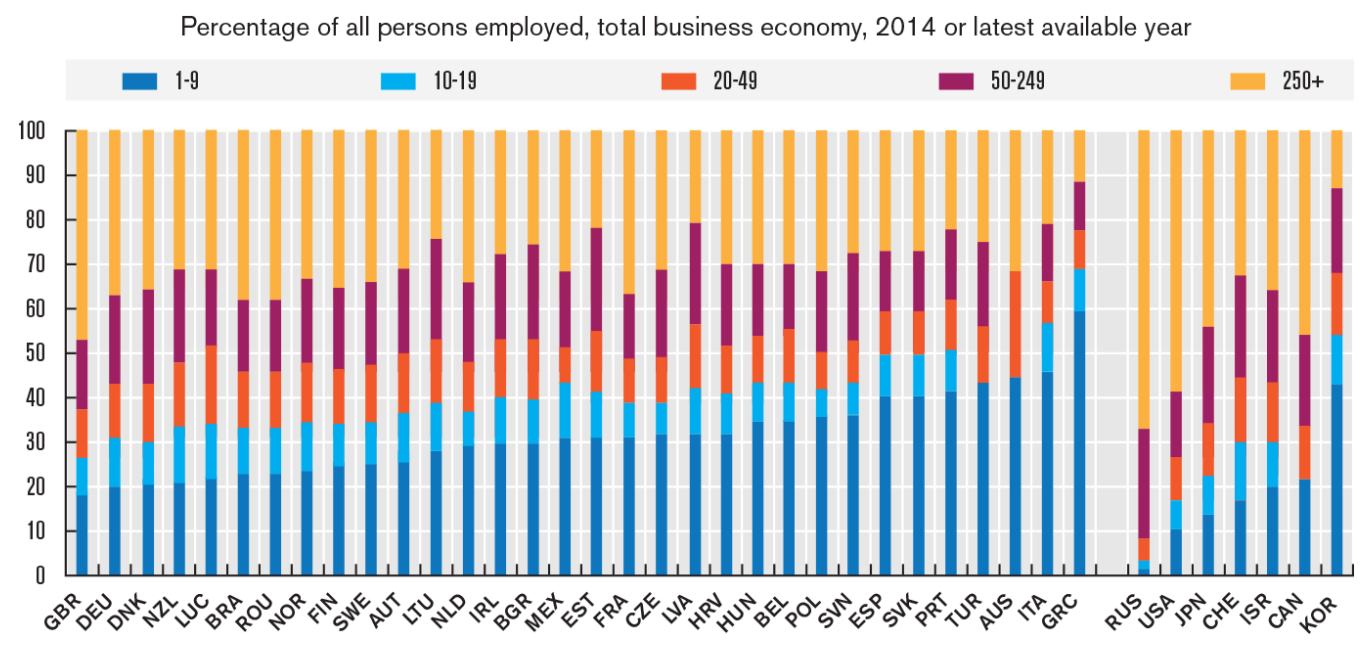

Figure 3: SMEs are the main source of jobs in the business sector (OECD, 2017)

Taking such information into account the importance of SMEs in the global economy and local communities becomes clear. And, because of their innate disadvantages relative to large corporation, it only makes sense to afford them greater support for their survival and growth. CTEs like BizX in conjunction with other economic policies can play an important part in supporting their health.

\section{- Economic Development Framework -}

Let us return to Greco's economic plan that was discussed in the literature review. His five-point plan (see appendix 1 ) is too broad to discuss in its entirety and instead I will amplify point one and four based on my findings and broader readings. 


\section{Point 1: Import substitution}

Greco proposes the launch of a comprehensive "buy local" campaign that would map all sectors of local and regional business economic resources, and commercial relationships. All data would be collected into an open and centralized database where local and regional businesses could access it. Municipal governments, nonprofits, social entrepreneurs, and activists would also be included as stakeholders in the process to ensure comprehensive buy in and support.

As discussed, a common network dissatisfaction throughout my research was the lack of businesses with which members could spend their BizX dollars. Such limitations were geographical and product and service types tilted towards retail. A truly effective buy local campaign that partnered with CTEs would not only link retail services but also identify every type of businesses in a supply chain. Manufacturing, wholesalers, and others ought, where possible, be brought into the network to make the power of CTEs more holistic and as such, more resilient. However, the large fees that BizX charges preclude this type of networking. If supply chains are to be incorporated they would need to be reduced substantially.

Another way to do this might be for an economic development agency to support the development of a nonprofit or for-social-benefit CTE. This would certainly allow for the reduction of fees because of the elimination of profit or at least the lowering of it. A local agency could also help in the creation of a local government's own CTE. The meeting of unmet demand with excess supply would generate economic growth and additional sales tax revenue. Such connections would also bring useful knowledge spillovers from minimally linked or unlinked areas that were evidenced by Ying Gao who 
researched the Banco Palmas CC in Brazil. ${ }^{26}$ Gao states that the Banco Palmas "effectively serves as a local knowledge bank" because of the close ties between the banks stakeholders and the community it serves. (2014, p. 48) Such transfers connected local resources and talents and "generated and circulated otherwise inaccessible knowledge relevant to the community." (2014, p. 68) Thus, knowledge transferences are possible by CCs.

\section{Point 4 - Supporting Financial Structures}

Greco understands his previous points alone cannot by themselves create the type of resilience and economic health for communities. A financial architecture for truly localized investments and savings need to be in place.

A limitation that I have seen in many CTEs is their propensity to frame themselves too narrowly. Their marketing defines them primarily as "barter" companies when in truth they are more than that. CTEs should broaden their self-definition and look at themselves as fintech firms that promote not just trade exchange but alternative forms of lending. CCs should be considered as part of the financial tools that a CDFI can offer SMEs. One way might be to collaborate with banks to invest in loan pools and consortiums. A CTE could partner with a CDFI and coordinate loans that neither would be able to make by themselves. (FDIC) BizX already makes loans of up to BX100,000 so this is quite possible.

26. The Banco Palmas is the hybrid of a CC and traditional bank that offers a local currency as one of its financial products. You can learn more about it at http://www.institutobancopalmas.org. 
Crowdfunding could be another viable fintech instrument for CTEs to help SMEs and startups. It has grown from \$203 billion in 2016 to \$294 billion to in 2017 worldwide and is expected to climb to $\$ 686$ billion by 2022. (Statistica) Partnering with crowdfunding sites such as 40 billion and Fundable to offer support for SMEs could be seen as a worthwhile investment for CTEs.

\section{Tax and Levy Acceptance}

Probably one of the more unusual forms of usage although certainly not unprecedented (as seen with the Wörgl and more recently the Brixton Pound) is the acceptance by local governments of a CTE currency for taxes and fees such as business licenses. ${ }^{27}$ This would alleviate expenses especially for small businesses but could prove especially useful during times of economic crisis when liquidity is in low supply.

All of these recommendations are well within the range of existing economic development frameworks. However, Greco's larger points of the proliferation of a regional currency in the USA are to my knowledge nowhere in sight. Most of the current interest about CCs surrounds the rise of cryptocurrencies that are not tied to any form of real wealth and are certainly not directly tied to the wellbeing of SMEs. In addition, beyond Lietaer's white paper on the Terra (2004), I know of no substantial projects in motion regarding a global currency.

27 It should be noted that only local municipalities can collect taxes in a CC as it is illegal for states to do so. (Mauldin, 2015) However, this does not preclude the payment of state fees or fines. 


\section{CLOSING THOUGHTS}

\section{- Lowering Fees -}

In addition to the expansion of the network, it is clear that a road to greater adoption of BizX and CTE's in general would be the lowering of its transaction fees. Their 12-15 percent fee between buyer and seller was consistently remarked on and disliked by BizX's members. It was also the key component to the inflationary effect that keeps it from parity with the US dollar. However, this might be overcome with a different pricing structure. Sardex has had notable success with a different payment model that relies heavily on subscription and initiation fees and not pay per transaction as BizX does. Initiation fees are based on the size of the business and range from $€ 150$ to $€ 1,000$ and membership fees are based primarily on turnover and range from $€ 350$ to $€ 2,500$. (Greco, 2015) Perhaps a similar payment structure might bring down the cost of using BizX thereby increasing its existing use by current members and helping to support its proliferation in the current network and a larger supply chain.

\section{- Possible Threats to CTEs -}

The failure of CTEs may come from their own success such as in the case with the Wörgl where its potential as a competitive threat to the state-run currency caused it to be squashed by Austria's treasury. So far this does not seem to be the case as CTEs in the USA are not anywhere close to competing with the power of the dollar. In addition, CTEs in the USA are self-policing and have successfully worked to report all transactions to the IRS thereby avoiding tax evasion problems and government regulatory controls. However, despite their diligence CTEs are facing new regulatory challenges. A recent 
news article by IRTA has warned that the cryptocurrency frenzy over the past few years is posing a new a new threat to CTEs. They are now being denied access to credit from banks because of their misperception that they are money transmitters. (IRTA, 2018) There is even an instance whereby a bank terminated its relationship with a CTE. Since CTEs in the USA have already undergone a process of consolidation, another threat could be they are acquired by the existing financial regime and dissolved. Or, used by them to make a profit thereby reinforcing their power. When BizX senior managers were asked about these possibilities Hanson had not given it much thought and Smith did not find the latter of particular concern asserting that the economic net benefit (assuming they were not dissolved) would still be significant despite such acquisitions. However, if CTEs are to grow and thrive such concerns ought to be examined. 


\section{CONCLUSION}

This paper has examined the underlying attitudes and motivations of the BizX CTE and concludes that its members are motivated to use it primarily because of its economic value. BizX's ability to help businesses grow, weather economic disruptions, and pay for costly business and personal expenses is notable.

However, its sincere attempt to engender a deeply connected and socially engaged business community came up overwhelmingly short for the majority of members interviewed. Despite this, its potential as economic tool is clearly evidenced and should be combined with other tools in a larger economic development toolbox that incorporates CDFIs, fintech alterative lending, and other self-reliance economic strategies for the creation and ongoing health and resilience of SMEs. In addition, to improve BizX's effectiveness, it and other CTEs need to significantly decrease their fees in order to encourage their use within their current network and a possible larger supply chain. Finally, such effectiveness and the resilience of SMEs could be further enhanced if local and regional governments would be willing to accept CTE currencies in payment of taxes and levies. 


\section{BIBLIOGRAPHY}

Bartik, T. (2005) Solving the Problems of Economic Development Incentives. Journal of Growth and Change, Vol. 36, No. 2, 139-166.

Blanc, J. (2011) Classifying "CCs": Community, Complementary and Local Currencies' Types and Generations. International Journal of Community Currency Research, Vol. 15 (D) 4-10.

Bindewald, L., Martin, A., \& McCann, D. (2015). People Powered Money - Designing, Developing and Delivering Community Currencies. New Economics Foundation. London. Retrieved from http://neweconomics.org/2015/05/people-poweredmoney/

BizX. (n.d. a) Retrieved 23 July 2017. https://my.bizx.com/Home

BizX. (n.d. b) Retrieved 23 July 2017. https://www.bizx.com/about/

BizX. (n.d. c) Retrieved 13 April 2018. https://www.bizx.com/how-it-works/

BizX. (n.d. d) Retrieved 13 April 2018. https://www.bizx.com/benefits/

BizX. (n.d. e) Retrieved 5 January 2018. https://www.bizx.com/pricing/

Bristol Pound. (n.d.) Retrieved 26 November 2017. http://bristolpound.org

City Data (n.d.) Retrieved 12, 2018. http://www.city-data.com/states/Montana-Locationsize-and-extent.html

Collom, E. (2007) The Motivations, Engagement, Satisfaction, Outcomes and Demographics of Time Bank Participants: Survey Finding from a U.S. System. International Journal of Community Currency Research, Vol. 11, 36-83.

Cresti, B. (2005). US Domestic Barter: An Empirical Investigation. Applied Economics, Vol. 37, 1-11. 
De La Rosa, J. \& Stodder, J. (2015) On Velocity of Several Complimentary Currencies. International Journal of Community Currency Research, Vol. 9, 114-127.

Eberts, R. (2005) Local Governance and the Drivers of Growth. OECD. Retrieved from http://www.oecd.org/leedforum/publications/Local $\% 20$ Governance $\% 20$ and $\% 20$ the $\% 20$ Drivers $\% 20$ of $\% 20$ G rowth.pdf

Gao, Y. (2014) The Local Knowledge Bank: Uncovering the Processes and Networks of Social Innovation at Brazil's First Community Bank [Masters thesis] Dspace at MIT. Retrieved from https://dspace.mit.edu/handle/1721.1/90097

Graeber, D. (2014) Debt: The First 5000 Years. Melville House Publishing.

Greco, T. (2008) The End of Money and the Future of Civilization. Chelsea Green Publishing. Kindle version

Greco, T. (2015, August 20) Sardex, An Emerging Model for Credit Clearing Exchanges. Beyond Money. Retrieved from https://beyondmoney.net/2015/08/20/sardex-anemerging-model-for-credit-clearing-exchanges/

Holder, S. (2018, February 12). To Fund the Resistance, Berkeley Turns to Cryptocurrency. Citylab. Retrieved from https://www.citylab.com/equity/2018/02/berkeleycrypto/552884/?utm_source $=$ SFFB

Hughes, N. (2015). The Community Currency Scene in Spain. International Journal of Community Currency Research, Vol. 19, 1-11.

Imbroscio, D. (1995) An Alternative Approach to Urban Economic Development: Exploring the Dimensions and Prospects of a Self-Reliance Strategy. Urban Affairs Review, Vol. 20, No. 6, 840-867. 
IRTA (n.d.) Retrieved 3 April 2017. IRTA Fact Sheet. Retrieved from https://www.irta.com/about/irta-fact-sheet/

IRTA (2018) IRTA Issues Warning about Barter Related Cryptocurrencies. Retrieved from https://www.irta.com/2018/04/irta-issues-warning-about-barter-relatedcryptocurrencies/

Ethereum (n.d.) Retrieved 29 November 2017. https://www.ethereum.org

Kennedy, M (2004) Retrieved 6 June 2017. Regio Complements Euro: New Paths to Sustainable Prosperity. Schumacher Center for a New Economics. http://www.centerforneweconomics.org/publications/regio-complements-euronew-paths-sustainable-prosperity

Krugman, P. (2015, January 30). Europe's Greek Test. Retrieved from http://www.nytimes.com/2015/01/30/opinion/paul-krugman-europes-greektest.html?_r=0

Labour Business (2013, November 20) New Cooperative Banking Model, Empowering Communities Swiss Style. Retrieved from http://fig.org/new-cooperative-bankingmodel-empowering-communities-swiss-style/

Leigh, N. Blakely, J. (2017) Planning Local Economic Development. (6 $6^{\text {th }}$ ed.) Thousand Oaks, CA. Sage. Google Books version

Lietaer, B. (2004) The Terra TRC [White Paper]. Retrieved from http://www.lietaer.com/2010/01/terra/

Lietaer, B., \& Hallsmith, G. (2009). Community Currency Guide: What Is a Community Currency? Retrieved from http://www.lietaer.com/2009/12/community-currencyguide

Lietaer, B., \& Ulanowicz, R., \& Goerner, S. (2009). Options for Managing a Systemic Bank Crisis. SAPIENS, Vol. 2(1), 1-15. 
Lietaer, B. \& Belgin, S. (2010) New Money for a New World. Qiterra Press. Kindle version

Littera, G. Sartori, L. Dini, P. \& Antoniadis, P. (2017) From an Idea to a Scalable Working Model: Merging Economic Benefits with Social Values in Sardex. International Journal of Community Currency Research, Vol. 21, 6-21.

Lindstrom, C. \& Witt, S. (2004) Local Currencies in the 21st Century: Understanding Money, Building Local Economies, Renewing Community. [Conference report] Schumacher Center for a New Economics. Retrieved from http://www.centerforneweconomics.org/publications/local-currencies-21stcentury-understanding-money-building-local-economies-renewing-com

Mauldin, R. (2015) Local Currency for Community Development: Policy Barriers and Support. Journal of Community Practice. Vol. 23, 462-476.

Martignoni, J. (2015). Cooperation and Intertrade Between Community Currencies: From fundamentals to Rule-making and Clearing Systems, Including a Case Study of the Zurich Area, Switzerland. International Journal of Community Currency Research, Vol. 19, 137-151.

Marvasti, A., \& Smyth, D. (1998). Barter in the US economy: A Macroeconomic Analysis. Applied Economics, Vol. 30 (8), 1077-1088.

Matthews, T. (2017, August 21). Ask: BizX's Bob Bagga. Retrieved from http://425business.com/bob-bagga/

Nation Master (n.d., a) Retrieved 12 April 2018. http://www.nationmaster.com/countryinfo/profiles/Germany/Geography

Nation Master (n.d., b) Retrieved 12 April 2018. http://www.nationmaster.com/countryinfo/profiles/Switzerland/Geography 
Nation Master (n.d. c) Retrieved 12 April 2018. http://www.nationmaster.com/countryinfo/compare/Germany/United-States/Geography

North, P. (2010) Local Money: How to Make It Happen in Your Community. Transition Books. iBooks version

OECD (2017, June 7) Enhancing the Contributions of SMEs In a Global Economy. The Organisation for Economic Co-operation and Development. Retrieved from https://www.oecd.org/mcm/documents/C-MIN-2017-8-EN.pdf

Osgood, J. Opp, S. \& Bernotsky, L. (2012). Yesterday’s Gains Versus Today’s Realties: Lessons from 10 Years of Economic Development Practice. Economic Development Quarterly, Vol. 26 (4), 334-350.

Otero-Iglesias, M., \& Steinberg, F. (2013). Is the Dollar Becoming a Negotiated Currency? Evidence from the Emerging Markets. New Political Economy, Vol. 18(3), 1-28.

Sabeti, H. (2011, November). The For-Benefit Enterprise. Harvard Business Review. Retrieved from https://hbr.org/2011/11/the-for-benefit-enterprise

Sardex. (n.d.) Retrieved 4 April 2018. https://www.sardex.net/il-gruppo/?lang=en

SCNE (n.d.) Retrieved 3 April 2018. http://www.centerforneweconomics.org/content/robert-swann

Seyfang, G. \& Longhurst, N. (2013). Growing Green Money? Mapping Community Currencies for Sustainable Development. Ecological Economics, Vol. 86, 65-77.

Stodder, J. (1998). Corporate Barter and Economic Stabilization. International Journal of Community Currency Research, Vol. 2, 1-11.

Stodder, J. (2009). Complementary Credit Networks and Macroeconomic Stability: Switzerland's Wirtschaftsring. Journal of Economic Behavior and Organization, 72(1), 79-95. 
Stodder, J \& Lietaer, B. (2016). The Macro-stability of Swiss WIR-Bank Credits: Balance, Velocity, and Leverage. Comparative Economic Studies, Vol. 58, 570605.

Statistica (2018) Retrieved 22 February 2018.

https://www.statista.com/outlook/399/100/alternative-lending/worldwide\#

Swann, R. (2001) The Autobiography of Robert Swann. Schumacher Center for a New Economics. Retrieved from http://www.centerforneweconomics.org/content/robert-swann/autobiographychapter24

Trading Economics. (n.d.) Retrieved 10 December 2017. https://tradingeconomics.com/united-states/capacity-utilization

Uzialka, A. (2012, December 27). Businesses Working to Generate Real Value in Cryptocurrency. News Daily. https://www.businessnewsdaily.com/10480cryptocurrency-businesses-real-value.html

Williamson, T, Imbroscio, D. \& Alperovitz, G. (2002) Making a Place for Community. Great Britain, Routledge. iBooks version

Wir (2018. a) Retrieved 16 April 2018. https://www.wir.ch/ueberwir/medien/medienmitteilungen/medienmitteilung/viac-app-wir-bank-lanciertdigitale-vorsorgeloesung/

Wir (2017. b) Retrieved 16 April 2018. https://www.wir.ch/bank/private/

World Bank. (n.d.) Retrieved February 19, 2018.

http://www.worldbank.org/en/topic/smefinance 


\section{APPENDIX:}

\section{Expansion of Greco's Five-Point Plan}

POINT 1: The launch of a comprehensive "buy local" campaign that would map all sectors of local and regional business economic resources, and commercial relationships. All data would be collected into an open and centralized database where local and regional businesses could access it. Municipal governments, nonprofits, social entrepreneurs, and activists would also be included as stakeholders in the process to ensure comprehensive buy in and support.

POINT 2: The formation of direct credit clearing exchanges. Such exchanges exist throughout the country and around the globe and their track record is well-established.

POINT 3: The formation of a regional association that would agree to a uniform credit instrument so that intratrade (trade between regions) was possible between current exchanges and new ones. This could be in the form of vouchers or coupons but would likely take the form of a digital currency to address issues of efficiency such as portability and accounting.

POINT 4: CTEs and a unifying association alone cannot by itself create the type of resilience and economic health for communities. A financial architecture for truly localized investments and savings that could take the form of local or state banks, or Community Development Finance Institution (CDFI), or fintech alternative lending would be needed to raise capital and preclude the capital leakage that larger banks create.

POINT 5: Regional credit instruments as mentioned in point three would need to extricate themselves from established fiat currency and be tied to a standard of value that was based on a "concrete standard of value." (Greco, Chapter 13) In other words, a currency independent of any political state and based on basket of commodities (or some other form of real wealth value) would need to be created. This independence would immunize it from the inflationary effects of an existing fiat currency and its established unit would also allow for international trade."

\section{BizX Employee Interview Questions}

1. What is the history of your organization?

- How did it get started?

- What kind of need did you see that BizX could fulfill?

- What particular choices were made in designing the currency?

- Why were they made?

- How do you market BizX

2. How many BizX dollars are in circulation and what is the monthly monetary turnover

3. How much does BizX do in annual sales?

4. Who are BizX's competitors?

5. Why do businesses join BizX? What are its main benefits? What makes BizX different from other complementary currencies out there? 
6. Are there philosophical/political reasons besides economic that found BizX?

7. How did BizX help its members weather the GFC crisis or an economic downturn?

8. What sectors and business sizes gain the most benefit from using BizX?

- How do you engage businesses?

- How do you help communities?

9. What has been/are the greatest challenge with getting BizX members?

10. What has been/are the greatest challenges with getting BizX members?

- How has BizX overcome them.

\section{BizX Member Interview Questions}

1. What is the history of your organization?

2. How did you find out about BizX?

3. How long have you been a member of BizX?

- What percentage of sales do you do in BizX?

- What purchases do you tend to make with BizX?

4. What are the main benefits from using BizX?

5. Do you think that BizX influences who you buy from and who buys from you?

6. If you have used other currencies, how is BizX different or better or worse?

7. Did BizX help you weather an economic disruption?

- If so, in what way?

8. What have been/are the greatest challenge with using BizX? How have you overcome them?

9. Are there philosophical/political reasons besides economic that you use BizX?

10. Do you plan to continue using it?

- Do you recommend it to other businesses? 